\title{
Recent progress for silver nanowires conducting film for flexible electronics
}

\author{
Lu Zhang ${ }^{1} \cdot$ Tingting Song ${ }^{1} \cdot$ Lianxu Shi $^{1} \cdot$ Nan Wen $\cdot$ Zijian Wu ${ }^{2}$. Caiying Sun ${ }^{1} \cdot$ Dawei Jiang ${ }^{1} \cdot$ Zhanhu Guo $^{3}$ (D)
}

Received: 13 May 2021 / Accepted: 24 July 2021 / Published online: 31 July 2021

(c) Islamic Azad University 2021

\section{Abstract}

Silver nanowires (AgNWs), as one-dimensional nanometallic materials, have attracted wide attention due to the excellent electrical conductivity, transparency and flexibility, especially in flexible and stretchable electronics. However, the microscopic discontinuities require AgNWs be attached to some carrier for practical applications. Relative to the preparation method, how to integrate AgNWs into the flexible matrix is particularly important. In recent years, plenty of papers have been published on the preparation of conductors based on AgNWs, including printing techniques, coating techniques, vacuum filtration techniques, template-assisted assembly techniques, electrospinning techniques and gelating techniques. The aim of this review is to discuss different assembly method of AgNW-based conducting film and their advantages.

\section{Graphic abstract}

Conducting films based on silver nanowires (AgNWs) have been reviewed with a focus on their assembly and their advantages.

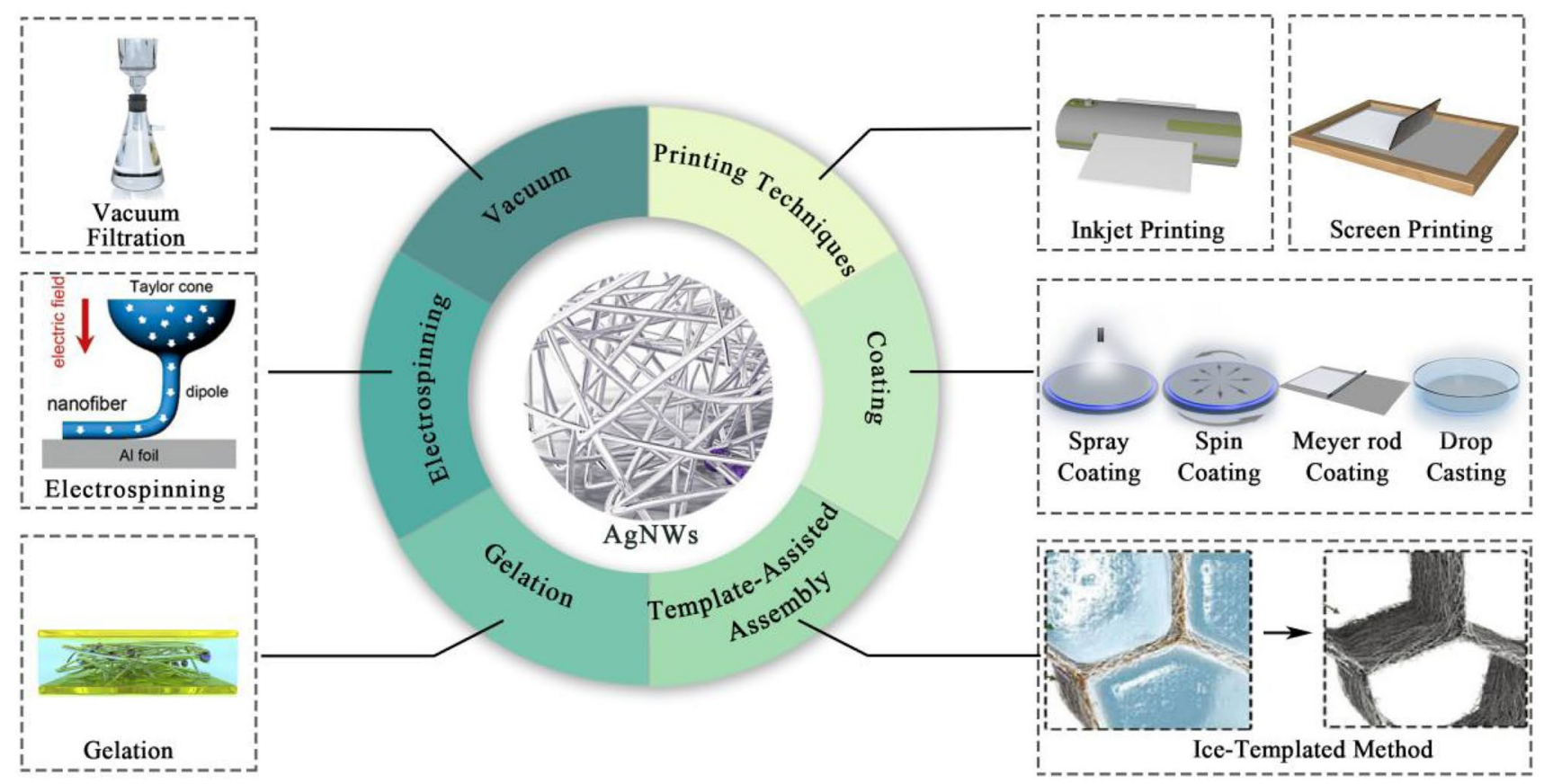

Keywords Silver nanowires conducting filns $\cdot$ Flexible electronics $\cdot$ Printed electronics $\cdot$ Electronic industry

Extended author information available on the last page of the article 


\section{Introduction}

In the past year, the global semiconductor industry has faced a huge challenge of insufficient production capacity. There are many factors affecting chip production, one of which is the work stoppings and production reductions of chip caused by COVID-19 and natural disasters (the Renesas Electric fire in Japan, the heavy snow in Texas, USA), on the other hand, the price of all kinds of chip raw materials continue to rise, such as polyvinyl chloride (PVC) prices rose by $60 \%$, glass prices rose by $40 \%$, copper prices rose by $48 \%$. In addition, the production capacity of high-end chips that rely on advanced manufacturing process is insufficient. Only Samsung and Taiwan Semiconductor Manufacturing Co., Ltd. (TSMC) have mastered the chips manufacturing process below $7 \mathrm{~nm}$, so the production capacity of chips with advanced manufacturing process is insufficient. The development of more advanced manufacturing processes and the mass production of high-end chips are far from assured. The shortage of chips has led to a shortage of CPUs, graphics cards, electronic devices and other commodities and a massive price hike, and has had a huge impact on the global electronics industry. This also reveals the following two problems. The current electronic industry is extremely dependent on the traditional electronic materials. The manufacturing techniques of traditional electronic materials, represented by silicon-based semiconductors, are about to encounter a bottleneck. Thus, there is an urgent need for new materials to make the electronics industry to leapfrog.

Throughout the past 100 years, the electronics industry has been developed rapidly [1-4]. Research in the field of electronics is becoming more and more thorough [5-13]. There has been a rapid rise in the literature about electronics and the publications on electronics from Scopus as shown in Fig. 1. The electronics industry has grown at a rapid rate since the 1940s. The electronics-related research papers have grown at a sequential growth rate of more than $1100 \%$ in

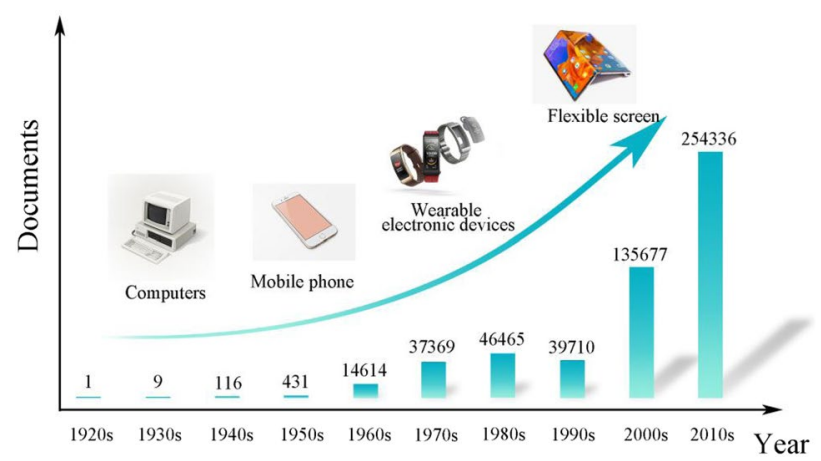

Fig. 1 Literature search results of different years in Scopus with electronics as the keyword, data from Scopus 1940s. The main reason is the development of electronic materials. The semiconductor material represented by $\mathrm{Si}$ promotes the development of computers. The development of Si chips (integrated circuits) has had the greatest impact on the development of the electronics industry. From the electronic tube computer (1946) covering more than 100 $\mathrm{m}^{2}$, to the mobile phone that can be held in one hand, everything depends on the advanced integrated circuit manufacturing process. With the invention of the transistor in Bell Laboratories in 1947, the electronics industry ushered in its first milestone. In 1958, the integrated circuit (IC) was invented. Since then, there has been a new outbreak in the electronics industry. As a result, research on electronic technology increased exponentially throughout the 1960s, with a sequential growth rate of 3,300\%. In 1964, Moore's Law was proposed by Moore, who predicted that the number of transistors on a chip would double every 18 months [14]. From the very beginning of the electron tube to the transistor to the small-scale IC to the present large-scale IC, Si seems to have become the natural material suitable for the IC because of the appropriate electrical properties, large reserves, mature purification process, stable chemical properties and other factors. The development of the electronic industry depends on the development of Si-based semiconductor materials, but at present $\mathrm{Si}$ material is about to face its physical limit, and the development of new materials is bound to bring revolutionary changes to the electronic industry [15].

On the other hand, the development of transparent conductive film (TCF) also plays a catalytic role in the development of the mobile electronics industry [16]. Among them, indium tin oxide (ITO) is a kind of TCF usually prepared by magnetron sputtering (MSP) [17]. Because of its high transmittance, good conductivity and stability, it has an irreplaceable position in the fields of touch panel, liquid crystal display, solar cell and so on [18-21].

With the development of ITO and its application on mobile phones, the sales of touch screen mobile phones have a leapfrog growth. Demand for electronics is shifting from stationary desktop computers to portable mobile devices. Some tasks that once needed to be handled on a computer have been gradually handled by mobile devices, and the direction of the electronics industry is gradually shifting toward lightweight and portable development. However, the problems faced by ITO mainly focus on high cost of raw materials. A large number of rare metal indium is used in the preparation of ITO. On one hand, the price is relatively high; on the other hand, the reserve of indium is limited, resulting in the high price of ITO. Compared with AgNWs, graphene and CNTs, the transmittance and conductivity of ITO is lower. ITO cannot withstand bending and stretching.

The development of nanomaterials has pushed the revolution of electronic industry [22-25]. More advanced processes have been developed in nanomaterials in the field of 
IC. The manufacture process of $\mathrm{MoS}_{2}$ transistors with the gate length of $1 \mathrm{~nm}$ was developed, this process prompted small gate length, which would integrate more transistors on an integrated circuit resulting in excellent performance of the device, the advantages of this process even exceeded that of the Si-based IC processes [26, 27]. Che et al. prepared a transparent electrode by polyaniline (PANI)-grafted CNTs exhibiting excellent conductivity and transmittance [28]. Compared with ITO, PANI-grafted CNTs transparent electrode also has a high flexibility, resulting in the development of flexible wearable device. All these advantages lead to the rapid development of nanomaterials and there is a trend to replace traditional materials [29-32].

With the further development of electronic technology, in many practical application areas, electronic devices need to be attached to the surface of living organisms to detect movement or body conditions, such as flexible displays, flexible supercapacitors, electronic skins, etc. [33-51]. To more closely combine electronic products with the human body and pursue the comfort of electronic devices, electronic devices need to be light, flexible, bendable and stretchable enough to adapt to body movements [52, 53]. And it needs to maintain stable work during the deformation process. Obviously, traditional rigid electronic materials will no longer be suitable for the flexible electronic field. Since 2018, the commercialization of flexible electronics has gradually started from mobile phones. Major manufacturers have launched flexible fold-screen mobile phones and promoted them vigorously.

Excellent electrical property, flexiblity, and lightweight make nanomaterials be the potential materials to replace traditional rigid materials in flexible electronics [54-66]. Carbon-based nanomaterials, such as graphene and CNTs stand out among the nanomaterials due to the unique structure of high transparency, high specific surface area and excellent mechanical properties and it show an irreplaceable position in the fields of electronics, energy storage and so on [67-95]. But its rather poor uniformity in large scales limit its applications [96]. In addition, the conductivity of carbon-based materials $(100-10,000 \Omega / \mathrm{sq})$ is relatively poor compared to a traditional metallic conductors. The comparison between the conductivity and transparency of common nanomaterials and ITO is shown in Table 1.

In recent years, silver nanowires (AgNWs) as a onedimensional (1D) metallic nanostructural materials has attracted much attention and shows a potential trend to replace traditional electronic materials [97-110]. AgNWs are a kind of silver-based metallic nanowires, which have been the focus of attention for several years due to not only the excellent electrical conductivity $\left(6.3 \times 10^{7} \mathrm{~S} \mathrm{~m}^{-1}\right)$ and thermal conductivity ( $429 \mathrm{~W} \mathrm{~m}^{-1} \mathrm{~K}^{-1}$ ) of AgNWs in electronic devices but also outstanding conductivity, transparency, thermal properties and mechanical properties
Table 1 Comparison of properties between ITO and different transparent conductive films

\begin{tabular}{lllll}
\hline & $\begin{array}{l}\text { Sheet resistance/ } \\
\text { conductivity }\end{array}$ & Transmittance & Year & References \\
\hline Graphene & $550 \mathrm{~S} \cdot \mathrm{cm}^{-1}$ & $70 \%$ & 2008 & {$[124]$} \\
Graphene & $10 \mathrm{~S} \cdot \mathrm{cm}^{-1}$ & - & 2011 & {$[125]$} \\
Graphene & $350 \Omega / \mathrm{sq}$ & $90 \%$ & 2009 & {$[126]$} \\
CNTs & - & $85 \%$ & 2004 & {$[127]$} \\
CNTs & $160 \Omega / \mathrm{sq}$ & $87 \%$ & 2006 & {$[128]$} \\
AgNWs & $20 \Omega / \mathrm{sq}$ & $80 \%$ & 2010 & {$[123]$} \\
ITO & $304 \Omega / \mathrm{sq}$ & $81 \%$ & 2016 & {$[129]$} \\
\hline
\end{tabular}

afforded by their high aspect ratio [111-122]. Because of the excellent electrical properties and good operability in solution, AgNWs act as conductors or circuits printed in some flexible electronics and it show the transmittance of $80 \%$ which have even match with ITO in some studies. AgNWs have become a potential material to replace ITO (Table 1). And due to the characteristics of flexibility, low resistance, good operability, etc., AgNWs have surpassed ITO in some applications. Thus, the AgNWs are proved much suitable for solar cells, which is because of the large difference between diffusive transmittance and specular transmittance compared with ITO. This phenomenon is caused by the light scattering effects [123].

Another reason for the widespread use of AgNWs for its convenient preparation [130]. AgNWs can be synthesized by a variety of simple techniques, such as ultraviolet irradiation method, hydrothermal method and solution-based synthesis, etc. [131-133]. Zhou et al. prepared AgNWs by an ultraviolet irradiation method [134]. The mixed solution of $\mathrm{AgNO}_{3}$ and PVA was put under UV light for $48 \mathrm{~h}$ and then the AgNWs (silver nanorods) with a diameter of 15-20 nm and a length of $350 \mathrm{~nm}$ were got. Xu et al. prepared AgNWs by hydrothermal method [132]. Hexamethylenetetramine aqueous was dropped into $\mathrm{AgNO}_{3}$ aqueous and then the gemini surfactant was added, after hydrothermal reaction at $100{ }^{\circ} \mathrm{C}$, the $\mathrm{AgNW}$ s were formed. The length of the AgNWs prepared in this method could reach $50 \mu \mathrm{m}$. Since the preparation method of AgNWs is more convenient, AgNWs have been already planned for mass production. This would also significantly reduce the cost of AgNWs, facilitating their replacement with traditional electronic materials.

All these properties make AgNWs be promising materials for the preparation of flexible stretchable electronic devices. However, the microscopic discontinuities make AgNWs attach to some carrier for practical applications. Relative to the preparation method, how to integrate AgNWs into the flexible matrix is particularly important. This review mainly discusses the assembly of conductive films of AgNWs, the 
fabrication methods of AgNW-based conducting film are still discussed in more details below $[135,136]$.

\section{Assembly of AgNW-based conducting film}

AgNWs could be dispersed in many solvents such as ethanol, isopropanol and water with good solubility, so the AgNW-based conducting films are often manipulated in a solution process [137-143]. The AgNWs solution is transferred to the flexible matrix to fabricate conducting films by techniques such as printing, coating, vacuum filtration, template-assisted assembly and gelation [144-149].

\section{Coating techniques}

Coating technology is widely used in the manufacture of thin films. In terms of the preparation of conductive films of AgNWs, the dispersion solution of AgNWs is usually scraped, dropped or sprayed on the surface of the substrate evenly, and then the solvent evaporation. After coating process, AgNWs network is formed on the substrate to form conductive pathway. Different coating methods often lead to different uniformity, electrical conductivity and transparency of the film, so we will discuss them as follows.

\section{Meyer rod coating}

Meyer rod coating is a kind of bar coating with the Meyer rod (a kind of metal bar wound around the metal wires). During the Meyer rod coating process, AgNWs solution is poured onto the surface of substrate, and then excess solution is scraped flat by Meyer rod (Fig. 2a). The thickness of AgNWs film determines the conductivity and transparency of the film, and the thickness could be tuning by varying the diameter of the metal wires around the bar.

$\mathrm{Hu}$ et al. prepared AgNWs electrodes by the Meyer rod coating process (Fig. 2b) [123]. The AgNWs ink was first poured onto the PET substrates and then coated by a Meyer rod. After drying by the infrared lamp, the AgNWs were formed uniformly on the polyethylene terephthalate (PET) substrates (Fig. 2c). And then a $20 \mathrm{~nm}$ thick Teflon was attached to surface of the AgNWs film to protect the electrodes. The electrodes exhibit excellent conductivity and transmittance, compared with ITO (Fig. 2d).

The distribution of AgNWs is uneven leading to a poor uniformity of conductivity of AgNWs conducting film when large-scale conducting films were made. Zhang et al. solved this problem through a dynamic heating process [150]. To improve the uniformity of the conducting film, the prepared film was moving repeatedly under a xenon lamp in $0.05 \mathrm{~m} / \mathrm{s}$ instead of the fixation. The temperature gradient of dynamic heating was more uniform in the dynamic heating process
(Fig. 2e, f). The uniformity of conductive film prepared through the dynamic heating process was compared with traditional Meyer rod coating. 25 regions were partitioned in the PET substrate of $20 \times 40 \mathrm{~mm}$. The conductivity of the 25 regions of the conducting film prepared by dynamic heating and traditional process was measured separately. The uniformity of the conducting film prepared by dynamic heating is better.

Another way to improve the conductivity of a conductive film is through post-processing. For example, Song et al. also fabricated a transparent conducting film by the Meyer rod coating method [151]. AgNWs with the concentrations from 2 to $0.5 \mathrm{mM}$ were coated by Meyer rod on glass or ITO substrate, respectively. Then the films were sintered at 150 , 200, 250, 300 and $400{ }^{\circ} \mathrm{C}$ (Table 2). The sheet resistance was sharply reduced from 80 to $6 \Omega$ /sq when the sintering temperature rose to $300^{\circ} \mathrm{C}$. But the AgNWs networks were broken at $400{ }^{\circ} \mathrm{C}$, which led to an open circuit. This is because the AgNWs began to weld together from $200{ }^{\circ} \mathrm{C}$, and the PVP began to be decomposed from $250^{\circ} \mathrm{C}$. The transmittance of the films could reach $65 \%$ and it is very smooth at the near-infrared regions (from 1100 to $1300 \mathrm{~nm}$ ), which is advantageous over ITO for solar cells. In addition, the contact resistance can also be effectively reduced by coating the surface of AgNWs with GO (Fig. 2g) [152]. As shown in Fig. 2h, the surface roughness of the conductive film is significantly reduced after GO is covered. At the same time, the environmental stability of the conductive AgNWs films covered with graphene is also improved (Fig. 2i).

\section{Spin coating}

Spin coating is the common process for preparing membranes in the laboratory. Spin coating is a process to form a uniform film on revolving platform by centrifugal force [153]. The volatile solvent evaporates during the rotation process and the film is left. The advantages of spin coating lie in fast fabrication of uniform and small films. However, it is hard to apply to large-scale industrial production due to the material loss during rotation and the thickness control is difficult. Lee et al. integrated AgNWs on the graphene surface through the spin coating technology, which effectively enhanced the thermal and electrical conductivity of graphene [154]. The transfer of electron/phonon energy carriers between polycrystalline organisms was effectively resolved, where AgNWs were equivalent to bridges (Fig. 3a, b).

Lang et al. prepared a transparent conductive films by a spin costing [155]. The polar organic-inorganic and the nonpolar organic-inorganic hybrid matrix were synthesized and then mixed with AgNWs. The mixed AgNWs ink was spun under different rotational speeds (from 300 to $5000 \mathrm{rpm}$ ). The thickness of the film could be controlled by the rotational speed. 


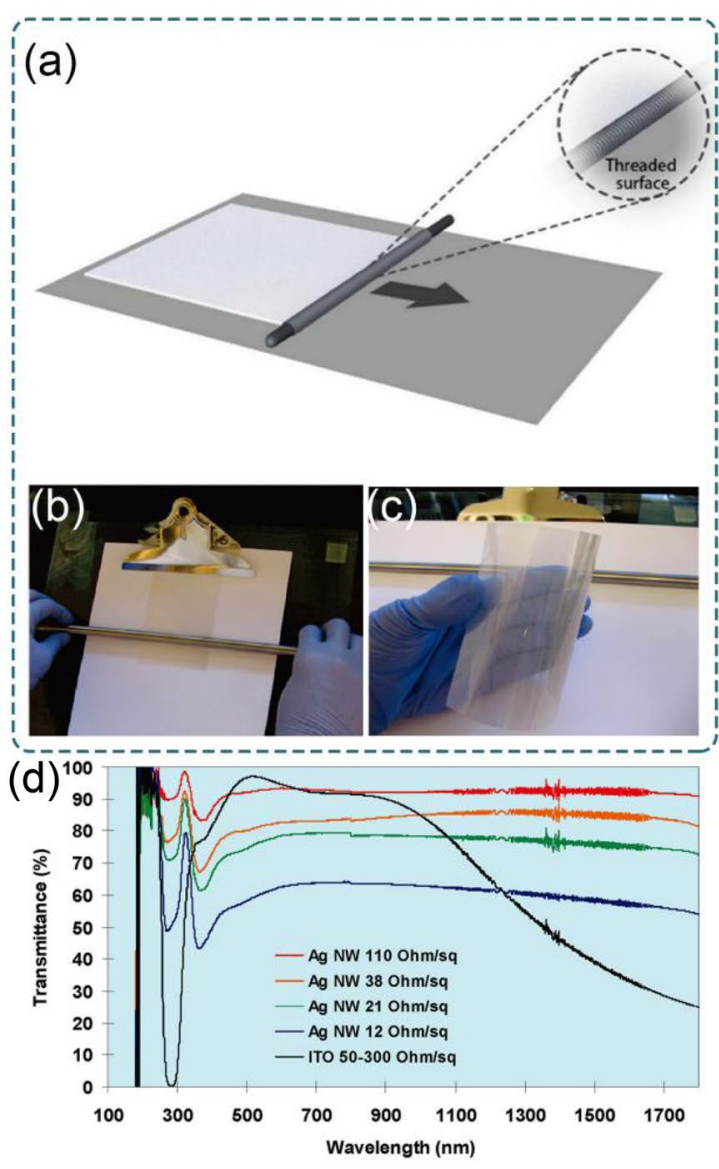

Fig. 2 a Schematic diagram of fabrication process of the Meyer rod coating, b actual operation diagram of fabrication process of the Meyer rod coating, $\mathbf{c}$ AgNWs were formed uniformly on the PET substrates, d the electrodes exhibit excellent conductivity and transmittance, compared with ITO. Adapted with permission from Ref. [123]. Copyright 2010 American Chemical Society. e The temperature distribution of static drying, $\mathbf{f}$ the temperature distribu-

Table 2 Sheet resistance under different sintering temperatures

\begin{tabular}{llllll}
\hline Sintering temperature $\left({ }^{\circ} \mathrm{C}\right)$ & 150 & 200 & 250 & 300 & 400 \\
\hline Rs of sample $4(\Omega / \mathrm{sq})$ & 80 & 45 & 15 & 6 & $/$ \\
\hline
\end{tabular}

\section{Spray coating}

In the spraying process, the AgNW dispersion is rapidly atomized through the nozzle under the action of compressed gas. The AgNWs are then uniformly attached to the substrate to form conductive network. Compared with spin coating and Meyer rod coating, spray coating can produce a more uniform conductive film.

AgNWs-exfoliated graphene (EG)-based transparent electrode with a low-surface roughness was prepared by Ricciardulli et al. through a spraying coasting process

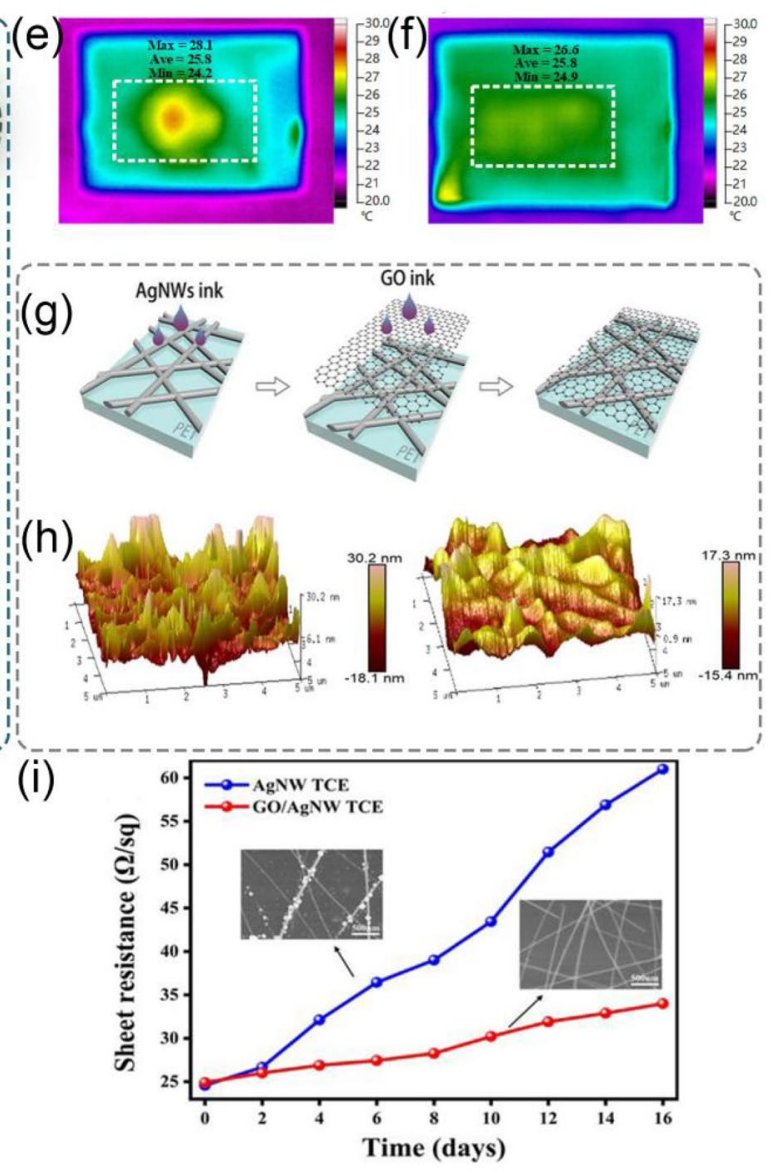

tion of dynamic heating. Adapted with permission from Ref. [150]. Copyright 2014 Yuan-Jun Song et al. g flowchart of preparation of AgNWs/graphene oxide (GO) composite conductive films, h 3D AFM images of AgNWs films and GO/AgNWs films, i resistance changes of AgNWS and GO/AgNWS films at $80{ }^{\circ} \mathrm{C}$ and $75 \% \mathrm{RH}$ for 16 consecutive days. Adapted with permission from Ref. [151]. Copyright 2020 IOP Publishing

[156]. In most cases, the drawback of contact resistance and rough surface of $\mathrm{AgNW}$-based conducting film is hard to avoid. The usual way to prove these problem is thermal annealing, high-force pressing and welding techniques [157-159]. However, exfoliated graphene was adopted to cover the surface of the AgNWs to reduce the contact resistance and surface roughness. In addition, the mechanical stability and chemical stability were also improved after introducing the EG. First, the AgNW solution was spray costed onto the substrates and then the EG flakes were also spray coated onto the surface of AgNW networks (Fig. 4). Compared with spin coating and vacuum filtration, spray coating is a more suitable method, which always led to a randomly arrangement of EG and the vacuum filtration always led to vacancies. The spray coating is the most suitable method for this case. 
Fig. 3 Schematic diagram of energy carriers propagated by materials before and after the addition of Indonesian rice noodles. a Polycrystalline graphene film; and b AgNW/ graphene film. Adapted with permission from Ref. [154] (a)

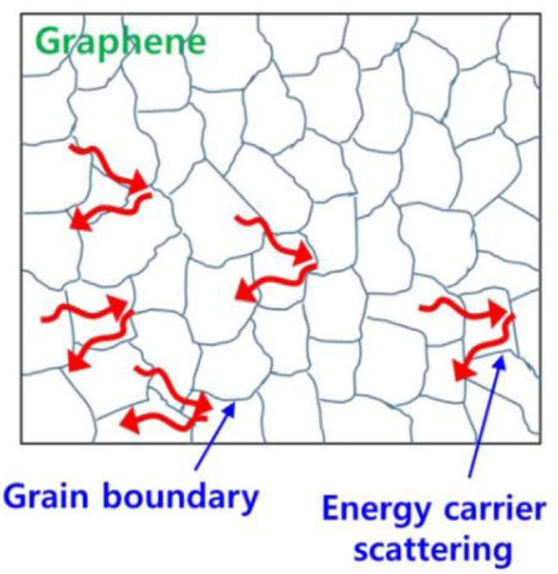

(b)

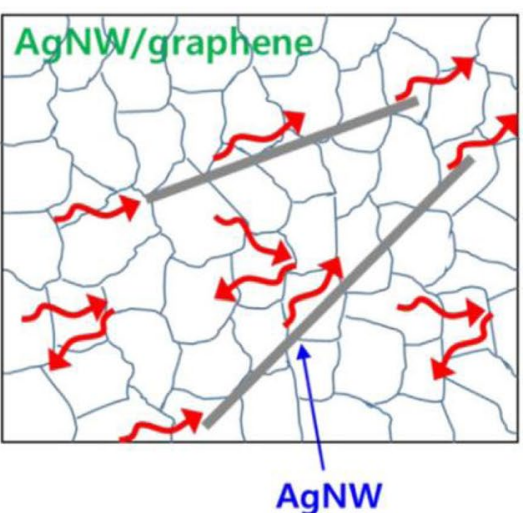

(a)
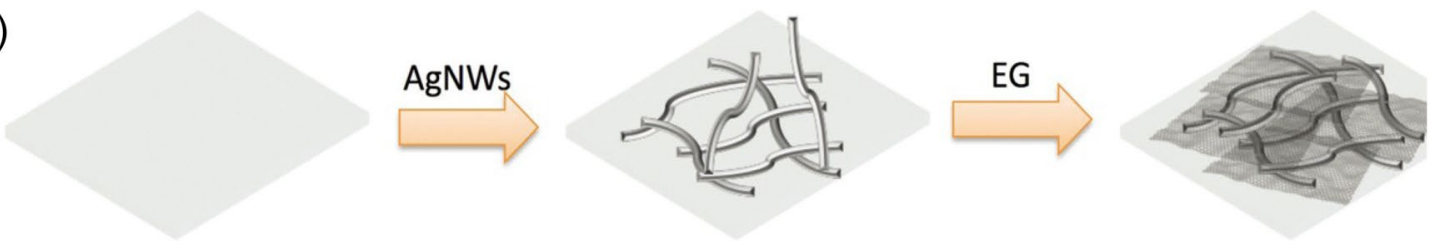

(b)
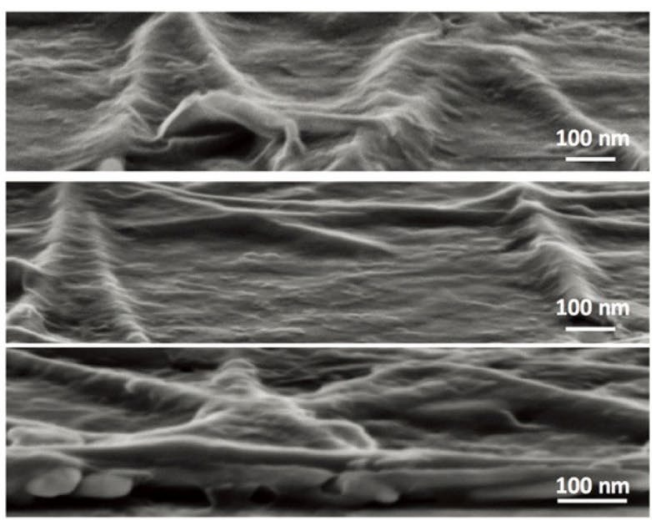

Fig. 4 a The fabrication process of the spray-coated AgNWs-EGbased electrode. b The SEM images of AgNW network coated by EG. c The change of sheet resistance during multiple bending of

\section{Drop casting}

When the thickness and uniformity of the film are not needed to be considered, drop casting is a better choice. The solution of AgNWs with a definite concentration is dropped onto a substrate to evaporate the solvent. After evaporating, the AgNWs are left on the substrate. Or it also could be transferred to another matrix. But it is hard to ensure the uniformity of $\mathrm{AgNW}$ conducting film during dropping, and the coffee rings may be introduced at the drying process. The thickness of film is also uncontrollable.

Jiang et al. prepared a self-healing sensor intercalated with AgNWs by the drop casting process [160]. The

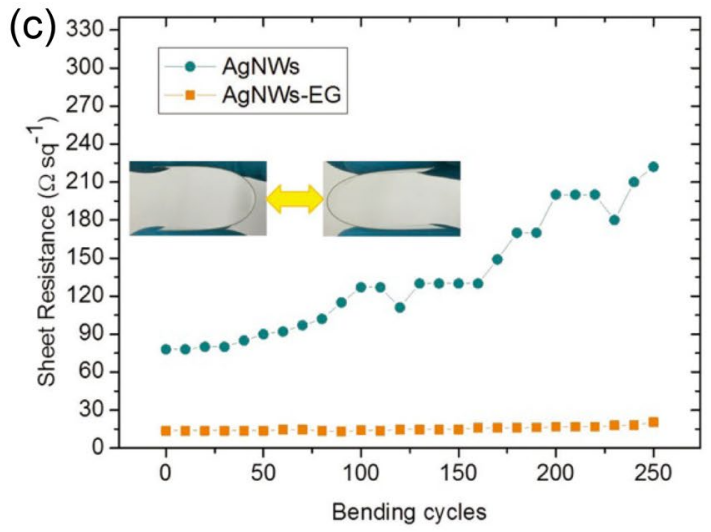

AgNWs and AgNWs-Eg flim. Adapted with permission from Ref. [156]. Copyright 2018 WILEY-VCH

AgNW solution was dropped at the tetrafluoroethylene (TFE) plate. The ambient temperature was then raised to $60{ }^{\circ} \mathrm{C}$ for $1 \mathrm{~h}$ to ensure the volatilization of solvent and the formation of AgNW film. Subsequently, a selfhealing polymer was attached to the AgNWs on the TFE plate and heated to $90{ }^{\circ} \mathrm{C}$ for $30 \mathrm{~s}$, and then a pressure of $0.2 \mathrm{MPa}$ was applied at $90{ }^{\circ} \mathrm{C}$ for $1 \mathrm{~min}$ to keep tightly contact of polymer and AgNW film (as shown in Fig. 5). The conductivity can be healed after damaging due to the discontinuous network of AgNWs which can can wriggle to the original location with the healing process of polymer substrate. Thus, no sintering or welding process is adopted. 
Fig. 5 The fabrication process of AgNW-based sensor. Adapted with permission from Ref. [160]. Copyright 2019 WILEY-VCH

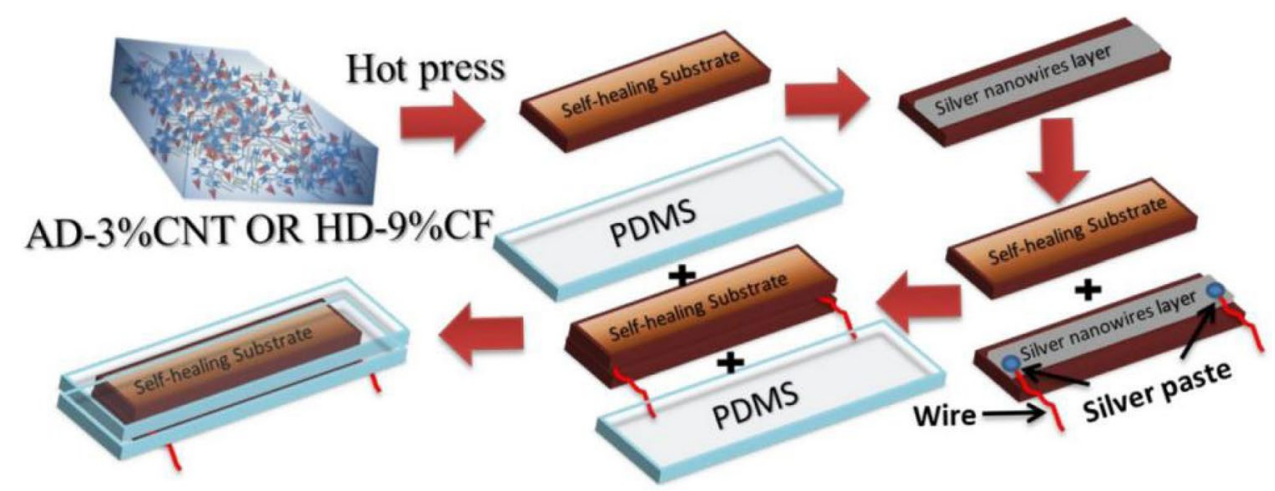

\section{Printing techniques}

Flexible printing electronics refers to a technology that combines printing technology with flexible electronics [161-166]. By means such as screen printing and inkjet printing, the conductive ink is transferred to a flexible substrate to form a specific pattern $[167,168]$. Flexible printed electronics have drawn much attention in recent years according to the large scale, low cost and versatile manufacturing. Compared with coating technology, flexible printing technology is suitable for the occasions with more refined patterns, such as flexible circuit board, flexible thin-film transistors, etc. [169-172]. The shape or pattern of conductor could also be precisely designed before fabricating. For example, Gao et al. realized the printing of piezoresistive pressure sensors on nanocellulose paper (NCP) as shown in Fig. 6a [173]. Cui et al. used the method of electrohydrodynamic (EHD) printing to achieve the minimum line width of $45 \mu \mathrm{m}$, as shown in Fig. 6b [174]. There have been a large number of flexible electronics fabricated by the printed electronics techniques including flexible displays, sensors and solar sell, etc. [175-180].

Printing technology involves several key technical points, i.e., the preparation of conductive ink, printing and postprocessing. According to different printing methods, printing technology can be divided into screen printing and inkjet printing.

\section{Screen printing techniques}

The screen printing technique is the most widely used printing techniques. The design of printing pattern is a unique feature of printing technology. In this process, a custommade screen with open areas of desired pattern is used as the print template. The AgNW ink is added on the custom-made screen. When a squeegee is scraped over the surface of the screen, the AgNW ink remains on the substrate through the open areas in the screen and the desired pattern forms. For example, Ali et al. used screen printing technology to design two kinds of patterns (i.e., straight and folded), and printed them on flexible thermoplastic polyurethane (TPU) to prepare flexible strain sensors (as shown in Fig. 6c) [181]. The size of the printed pattern is $28 \mathrm{~mm}$ long, $4 \mathrm{~mm}$ wide, and $0.8 \mathrm{~mm}$ line width, as shown in Fig. 6c. A more elaborate structure was designed in the work of Liang et al. [182]. A $10 \times 6$ thin-film transistor (TFT) array is screen printed on a flexible PET substrate with a resolution of up to $50 \mu \mathrm{m}$, as shown in Fig. 6d, e. Actually, the rheological behavior of ink affects the resolution of printing. The peak holding step (PHS) test was carried out to analyze the change in viscosity of three kinds of $\mathrm{AgNW}$ inks with different $\mathrm{AgNW}$ contents (i.e., $6.0 \%, 6.6 \%$ and $7.3 \%$ ), respectively. The shear rates were varied to simulate the scraping process and the recovery process (Fig. 6e). Once the squeegee scrapes the ink through the screen, the ink could flow through the screen due to the decreasing viscosity of ink. While, when the force of the squeegee disappears, the ink does not recover to the original viscosity immediately. This gives the ink time to level out. In contrast, the high viscosity ink has less time to level out, which lead to coffee rings, as shown in Fig. 6f. The low viscosity ink is inclined to achieve sharper print lines [183]. Xu et al. used AgNW ink with a low concentration (for example, $2.5 \mathrm{mg} / \mathrm{mL}$ ) and low viscosity $(0.74 \mathrm{~Pa} \cdot \mathrm{s}$ at shear rates of $10 \mathrm{~s}^{-1}$ ) to screen print a $2.5 \mathrm{~cm} \times 2.5 \mathrm{~cm}$ transparent electrode, and covered it with GO to ensure electrode stability [184]. The transparency of the prepared transparent electrode reaches $83.5 \%$ and the square resistance reaches $11.9 \Omega / \mathrm{sq}$. The authors applied it to a long-term wearable heart rate monitoring device.

\section{Inkjet printing techniques}

Inkjet printing is a common non-contact printing technology in our daily life [185]. Books, documents, pictures and so on can be printed by inkjet printing technique. Inkjet printing technique is crucial in printed electronics. Compared to screen printing technology, inkjet printing is more flexible in applications and is suitable for a variety of materials such as paper, glass, PET, TPU due to its non-contact 

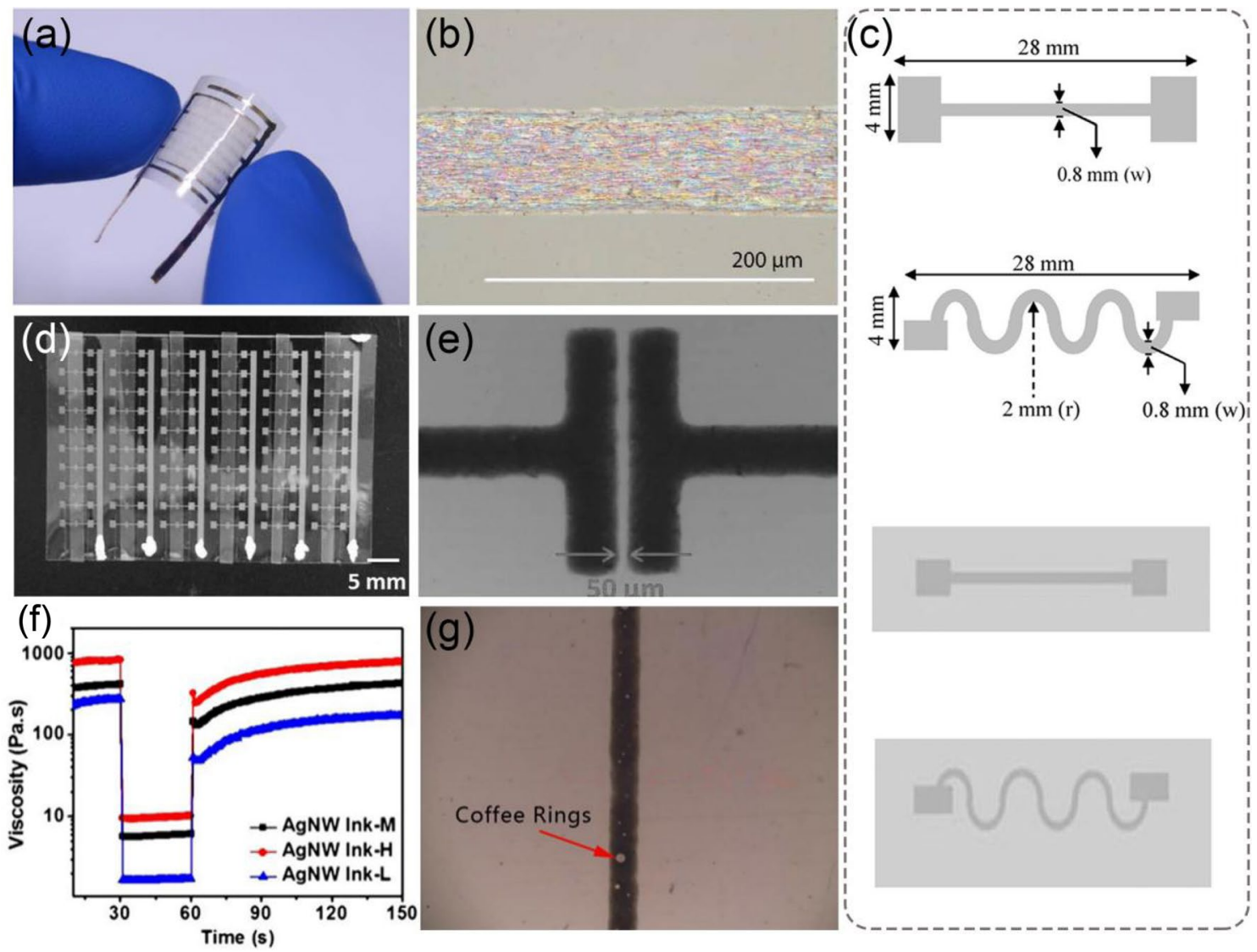

Fig. 6 a The piezoresistive pressure sensors prepared by printing silver nanowires on NCP. Adapted with permission from Ref. [173]. Copyright 2019 American Chemical Society; b optical images of AgNW lines printed on PDMS. Adapted with permission from Ref. [174]. Copyright 2009 Royal Society of Chemistry, c two patterns are printed by AgNWs on TPU, one of which is a straight line and the other is a wavy line (schematics and photographs). Adapted with

characteristics. It's worth noting that an ordinary commercial printer can complete the printing process of electronics.

Inkjet printing technique was demonstrated in Choi's work [186]. The inkjet printing process can be easily realized through a desktop inkjet printer (HP Deskjet 1010), as shown in Fig. 7a. In this study, a mixture of single-walled carbon nanotubes (SWNTs), activated carbon (AC) powders and AgNWs were mixed to form printing ink. The mixed ink was subjected to the sonication-driven scission process to avoid printer nozzle blockage caused by the long AgNWs and then the ink was printed on paper to form flexible solid supercapacitors and it had a good electrical performance, in the circuit it could light up an LED lamp, as shown in Fig. 7b, c. Cellulose nanofibril (CNF) was used as the primer layer sprayed onto A4 paper in advance to reduce the capillarity phenomenon of paper, which can improve the printing resolution. Generally, the surface of substrate plays an important role for printing electronics. For wetting substrates (such as A4 paper), the rough surface may induce permission from Ref. [181].Copyright 2018 Elsevier, d flexible TFT arrays prepared by screen printing of AgNWs, e The resolution of TFT Arrays can reach $50 \mu \mathrm{m}, \mathbf{f}$ the Rheological behavior of 3 kinds of $\mathrm{AgNW}$ inks and $\mathbf{g}$ the coffee rings of high viscosity ink appeared in the printing process. Adapted with permission from Ref. [182]. Copyright 2016 WILEY-VCH

the capillarity. The capillarity causes the ink to spread and reduces the resolution of printing. While for non-wetting substrates such as polyethylene terephthalate (PET), the poor adhesion for ink may lead to the formation of coffee ring. However the surface of the CNF primer layer is between wetting and non-wetting substrates, and there is no capillarity and coffee-ring appearance on the surface of CNF primer layer, as shown in Fig. 7d [186]. Similarly, Gao et al. used a nanocellulose paper with a smooth surface as a printing carrier [173]. Printing on NCPs, which have a smoother surface, yields sharper patterns than PET, as shown in Fig. 7e.

Compared with screen printing, because the ink needs to pass through the nozzle, inkjet printing has higher requirements for the size of the printed nanomaterial, the size of its requirements is usually long and its size is less than $1 / 50$ of the nozzle aperture. However, for the metal nanowires, because of the one-dimensional structure, the requirements are more loose. For example, Finn et al. used $2.2 \mu \mathrm{m} \mathrm{AgNWs}$ to carry out inkjet printing through a $21.5 \mu \mathrm{m}$ nozzle, and 

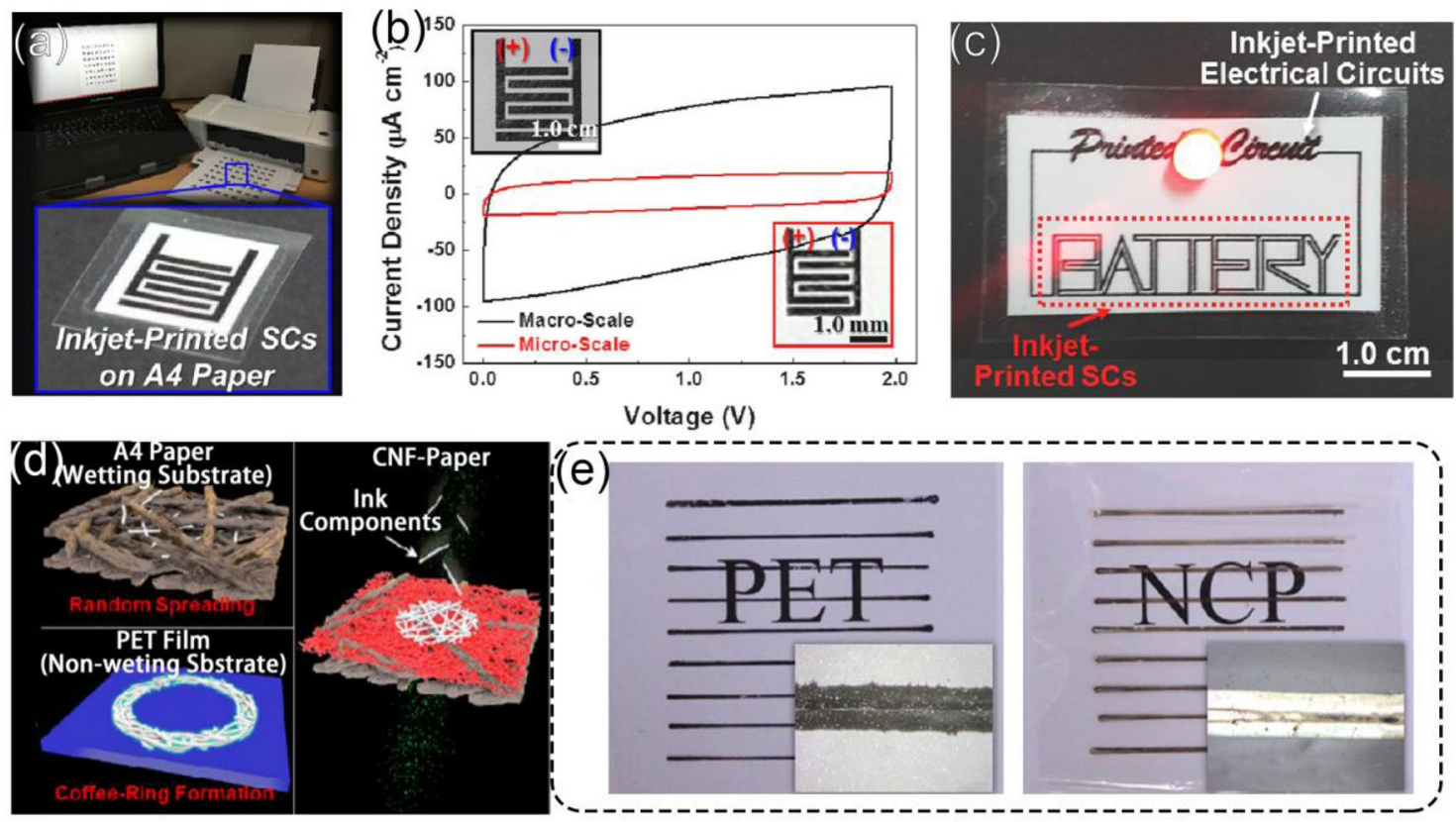

(f)

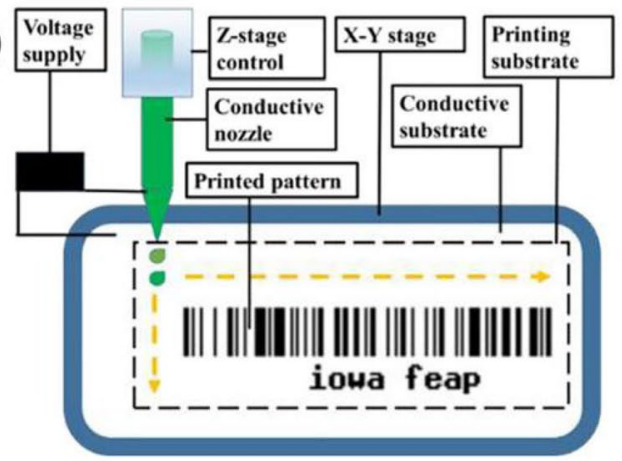

Fig. 7 a Inkjet printing on paper can be done using only commercial printers, $\mathbf{b}$ cyclic voltammetry curves of two printed supercapacitors of different sizes, $\mathbf{c}$ printed SCs are used to light a LED, $\mathbf{d}$ the influence of substrate on the effect of inkjet printing. Adapted with permission from Ref. [186]. Copyright 2016 WILEY-VCH, e AgNWS

achieved a line width of $1-10 \mathrm{~mm}$ and a thickness of $2 \mu \mathrm{m}$ [185].

Zhang et al. adopted electrohydrodynamic inkjet (E-Inkjet) printing to effectively improve the printing resolution, and the printing principle is shown in the Fig. 7f [187]. The print resolution of $30 \mu \mathrm{m}$ is achieved by applying a voltage between the nozzle and the substrate, as shown in Fig. $7 \mathrm{~g}$.

\section{Electrospinning}

Electrospinning process is the common way to fabricate 1D conductive nanofibers [188-198]. Electrospinning works in a similar way to e-Inkjet, where a strong electric field between the nozzle and the printing substrate transfers the solution from the nozzle to the printing platform. Unlike

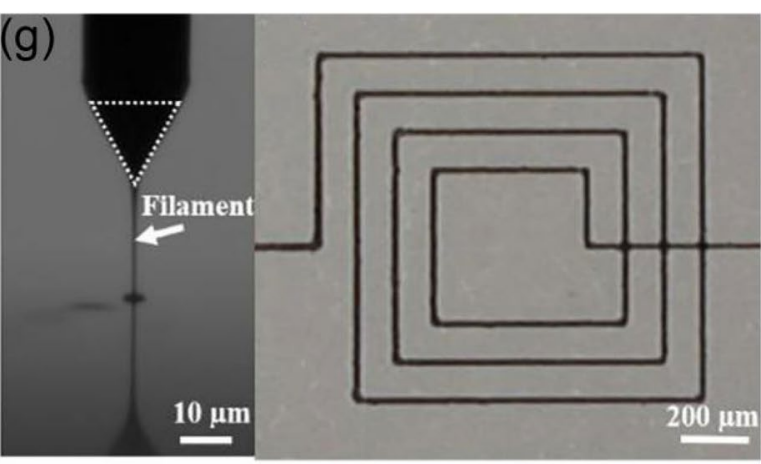

trace comparison diagram printed on PET surface and NCP surface. Adapted with permission from Ref. [173]. Copyright 2019 American Chemical Society, $\mathbf{f}$ the printing principle of E-inkjet printing and $\mathbf{g}$ print trace obtained by E-inkjet printing. Adapted with permission from Ref. [187]. Copyright 2021 Springer Nature

E-Inkjet, the solution used for electrospinning is usually a pre-polymerized solution of AgNWs mixed with a polymer. In this process, $\mathrm{AgNW}$ are mixed with a polymer solution, sprayed into a strong electric field to form small fibers and collected onto a substrate to form a conductive network.

Generally, the specific surface area of nanowires is large, and it is easy to be oxidized when exposed in the air, thus affecting the performance. Conductive films prepared by means of coating and printing need to be post-processed to isolate AgNWs from the environment. Electrospinning prevents oxidation by placing a polymer coating directly on the outside of AgNWs.

The electrospun AgNWs-polyvinylidene fluoride (PVDF) nanofibers were demonstrated by Cheon et al. [199]. The triboelectric nanogenerator (TENG) with AgNWs-PVDF has been fabricated by the electrospinning process. The AgNWs 
and PVDF were dissolved in the mixed solvent of N,N-dimethyl acetamide and acetone for $5 \mathrm{~min}$ of ultrasonic processing and $3 \mathrm{~h}$ of stirring to make sure the solution uniform. Then the electrospun process was performed (Fig. 8a, b,c). In the presence of an electrostatic field, the polymer solution is emitted from the needle tip (Taylor cone) to a collector (Al foil) for $2 \mathrm{~h}$. In the process, polymer fibers with the highly oriented crystalline polymer chains are formed. These nanofibers were collected and cut into $2 \times 2 \mathrm{~cm}^{2}$ nanofibers mat (Fig. 8d). The addition of AgNWs makes it easier to trap the charge and induce the tribocharges. (Fig. 8e). After thermal treatment at $160^{\circ} \mathrm{C}$ for $2 \mathrm{~h}$, the PVDF-AgNWs nanofibers mat was treated as the electrodes of TENGs and served as the negative triboelectric potential. The compact spinning technique was used to prepare a core sheath silver nanowire/polyvinylpyrrolidone [200]. Due to the presence of PVP coating, the nanofibers prepared have the properties of insulation. Pan et al. used the mixed solution of AgNWs and AgNPs to prepare a transparent conductive film through the near-field electrospinning process. The film reached $70 \%$ transparency and $0.032 \Omega /$ sq square resistance, which was similar to that of ITO [201].

\section{Vacuum filtration}

In vacuum filtration process, $\mathrm{AgNW}$ are prepared as dispersion and passed through the filtration funnel. Solvent flows over the membrane and AgNWs remain on the membrane to form an AgNWs network, which is then transferred to the substrate. Xu et al. prepared a transparent conductive film based on AgNWs [202]. The light transmittance of the prepared transparent conductive film can be adjusted from 65.6 to $87.5 \%$ and sheet resistance from 177.3 to $4.95 \Omega /$ sq by controlling the weight density of the silver nanowire solution.

Shen et al. fabricate a $\mathrm{AgNW}$ s and tungsten oxide $\left(\mathrm{WO}_{3}\right)$ based electrochromic electrode for supercapacitors by the vacuum filtration method [203]. First, the PDMS was spin-coated on the flexible PET substrate and it was pre-cured. Subsequently, the AgNWs ethanol solution was diluted by deionized water and then vacuum filtered on a filter membrane. The AgNWs film on the filter could be easily transferred onto the pre-cured PDMS. Then the $\mathrm{WO}_{3}$ was deposited on the flexible substrates with a $600 \mathrm{~nm}$ thickness. The composite electrode exhibits an areal capacitance of $13.6 \mathrm{mF} / \mathrm{cm}^{2}$ and corresponding specific capacitance of $138.2 \mathrm{~F} / \mathrm{g}$ when the scan rate is $10 \mathrm{mV} / \mathrm{s}$. And it also shows the electrochromic property. The color could be changed between dark blue and transparent when a negative (dark blue) or positive (transparent) bias potential is applied, respectively. This is caused by the reaction of the transformation between $\mathrm{WO}_{3}$ and $\mathrm{H}_{\mathrm{x}} \mathrm{WO}_{3}$ (Fig. 9).

In general, the silver nanowires of AgNWs films prepared by vacuum pumping and filtration are physically bonded, and the uniformity of deposition is difficult to be controlled, resulting in poor electrical conductivity. Mushtaq et al. deposited AgNWs in the poly(Ethersulfone) (PES) membrane first, and then electroplating the pristine AgNWs membrane with a layer of silver in the posttreatment method [204]. Electroplating treatment of the conductive film has a better uniformity and conductivity.
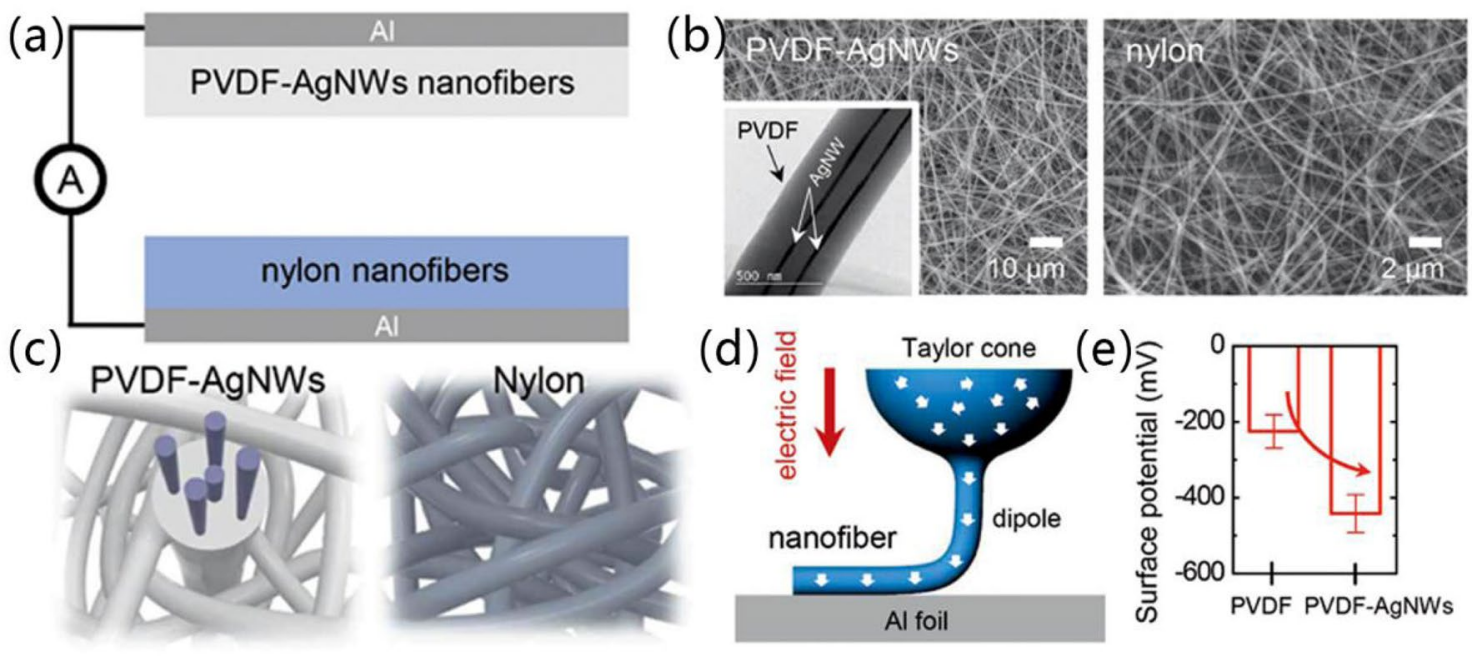

Fig. 8 a The schematic diagram of TENG, $\mathbf{b}$ the SEM images of PVDF-AgNWs and nylon, $\mathbf{c}$ the structure diagram of PVDF-AgNWs and nylon, $\mathbf{d}$ schematic illustration of electrospinning process, $\mathbf{e}$ the

surface potentials of PVDF and PVDF-AgNWs. Adapted with permission from Ref. [199]. Copyright 2017 WILEY-VCH 
Fig. 9 The fabrication process of the electrochromic electrode. Adapted with permission from Ref. [203]. Copyright 2006, The Royal Society of Chemistry

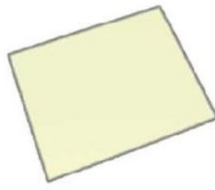

PET

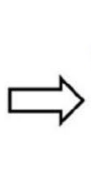

PDMS coated

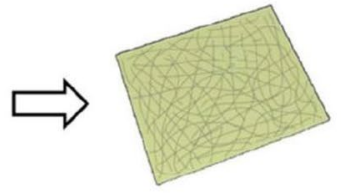

Ag NWs coated

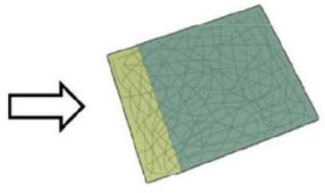

$\mathrm{WO}_{3}$ coated

\section{Template-assisted assembly}

Template-assisted assembly refers to the method of using templates to assemble some specific shapes or specific structures. Template-assisted assembly technology can usually obtain a three-dimensional ordered onlooker structure.

Physical template assembly is the common templateassisted assembly. The template is usually a polymer with a specific structure or a substance with a network structure, such as polyurethane, sponge, foam nickel, etc. PU is a commonly used template material in various polymer templates. On one hand, because PU is a common commodity foam material, on the other hand, because PU has a unique network structure. Ge et al. utilized commercial PU foam as a template to form a stretchable AgNWs conductor with a specific binary network structure [205]. The PU was immersed in the ethanol solution of AgNWs, with the evaporation of ethanol, the AgNWs were left on the surface of the PU to form a conductive network. The existence of this unique binary network enables PU/AgNWs to still exhibit a high conductivity of $19.2 \mathrm{~S} \mathrm{~cm}^{-1}$ under $50 \%$ strain. Another reason for choosing PU as a template is that it is easy to be removed. Wu et al. utilized PU as a template to assist in the preparation of graphene/AgNWs foam [206]. The PU template is immersed in an aqueous solution of GO and AgNWs. GO is then reduced to graphene by dopamine and attached to the foam surface together with AgNWs. Then the $\mathrm{PU}$ foam is formed by pyrolysis at $700{ }^{\circ} \mathrm{C}$. After removing the template, the material can still maintain the shape of the template (Fig. 10a).

In addition to polymers with specific structures, ice is often used as a template. Ice-template method is the common template-assisted assembly method to fabricate 3D AgNWs networks. In this process, AgNWs aqueous solution is frozen to make the water condense into ice crystals, and then the ice crystals are sublimated by vacuum drying
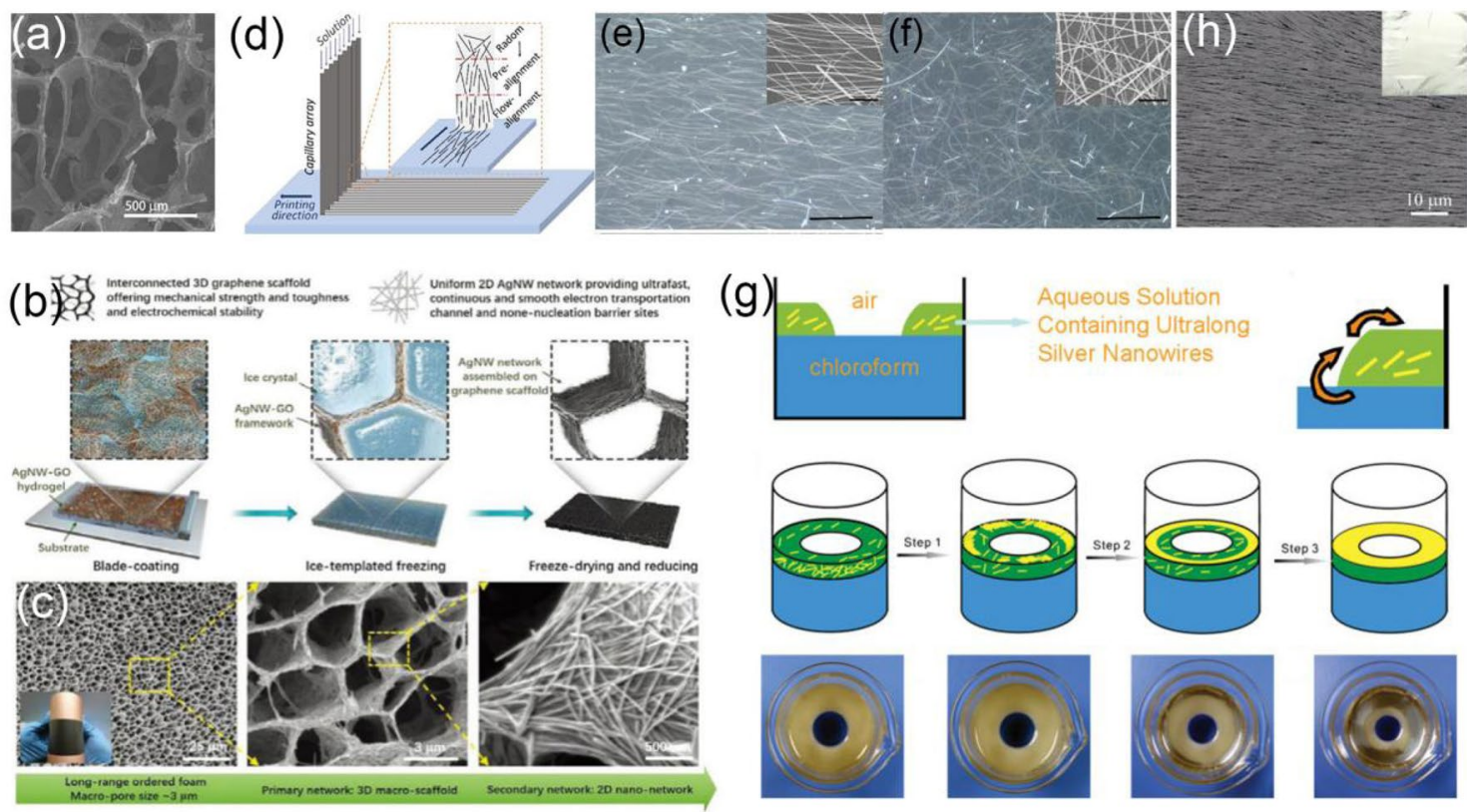

Fig. 10 a SEM image of graphene/AgNWs foam. Adapted with permission from Ref. [206]. Copyright 2014 American Chemical Society, $\mathbf{b}$ the schematic diagram of ice-templated process, $\mathbf{c}$ the SEM images of the 3D networks of AgNWs-GO skeleton under different magnifications. Adapted with permission from Ref. [207]. Copyright 2018 WILEY-VCH, d schematic diagram of the capillary-assisted fluidic assembly process, e optical microscopy images of AgNWs

prepared by CFA technique, $\mathbf{f}$ spray-coating technique. Adapted with permission from Ref. [208]. Copyright 2012 Royal Society of Chemistry, $\mathbf{g}$ three-phase interface assembly and its four-step principle display diagram and $\mathbf{h}$ the SEM images of the AgNWs conductive film prepared by three-phase interface assembly. Adapted with permission from Ref.[209]. Copyright 2010 WILEY-VCH 
technology to form 3D AgNWs networks. Ice-templated method was adopted by Xue et al. to prepare hierarchical AgNWs-graphene host for Li-ion batteries. The viscous mixed aqueous solution of AgNWs and GO was bladecoated onto substrate and then dipped in liquid nitrogen [207]. Small and orderly ice crystals were formed in the AgNWs-GO hydrogel. Subsequently, the freeze-drying process was carried, leaving the voids in the AgNWs-GO hydrogel during the sublimation of the small ice crystals. An ordered 3D network was formed (Fig. 10b, c).

Regular alignment of AgNWs is realized through capillary-assisted fluidic assembly (CFA) (Fig. 10d) [208]. The capillary array is used as a template for the self-assembly of AgNWs. When the AgNW solution flows through the capillary, the AgNWs will self-assemble along the direction of the capillary in the capillary. As the AgNWs flow out of the capillary, the AgNWs form a well-aligned conductive film on the substrate (Fig. 10e, f). The oriented AgNWs exhibit excellent anisotropic conductivity. In parallel, it exhibits far lower square resistance and higher transparency than randomly distributed $\mathrm{AgNWs}$ conductive films.

In other studies, the template does not refer to a specific shape of solid, but a specific interface structure. A specific water-oil-air interface is used as a template to achieve a special orderly oriented AgNWs film assembly by Shi et al. [209]. A water dispersion of AgNWs was dropped on the chloroform solution to construct a template with a threephase interface structure (Fig. 10g). The AgNWs realize a process from the water-oil interface to the water-oil-gas interface and then to the water-gas interface, during which they self-assemble into a film. The evaporation of chloroform at the oil-gas interface makes the pressure at the oil-gas interface lower than the water-oil interface, forming a pressure gradient $(\Delta \mathrm{P})$. The $\Delta \mathrm{P}$ causes the directional movement of AgNWs. The AgNWs assembled in this way have excellent regularity (Fig. $10 \mathrm{~h}$ ).

\section{Gelation}

The gelation is a method to construct 3D nanofiller network [210-212]. The AgNWs are first mixed with the precursor solution of hydrogels. Then the gelation reaction is carried out to fix AgNWs in the hydrogels to make the conductive pathway form. In this method, AgNWs are often lapped together in a three-dimensional manner, and higher concentrations are usually required to achieve conductivity improvement. This often leads to poor transparency.

Lim et al. prepared stretchable conductors with AgNWs and alginate hydrogels by the gelation methods [213]. The AgNWs and sodium alginate were mixed at $70{ }^{\circ} \mathrm{C}$, and then dried at $40{ }^{\circ} \mathrm{C} .0 .1 \mathrm{M} \mathrm{CaCl}_{2}$ aqueous solution was then added for 20 min to make sure the cross-linking between the alginate chains happening (Fig. 11). The conducting film exhibits excellent conductivity, which the impedance of the film is extremely stable and maintains the low value of $8.5 \Omega$. The conducting film could be cut into any shape by laser according to the actual usage (Fig. 11). The conductivity of AgNWs conducting film ( $\geq 0.3 \mathrm{wt} \%$ AgNWs) exhibits a stretch insensitivity when the strain is between 0 and $30 \%$. However, the color of the film shows opaque metallic silver, which makes the film hard to be used in the optical field.

\section{Conclusions and prospects}

With the development of flexible electronic, AgNWs as an important component of flexible electronics devices have shown the potential to replace or even surpass traditional conductors. However, there are still some factors that limit

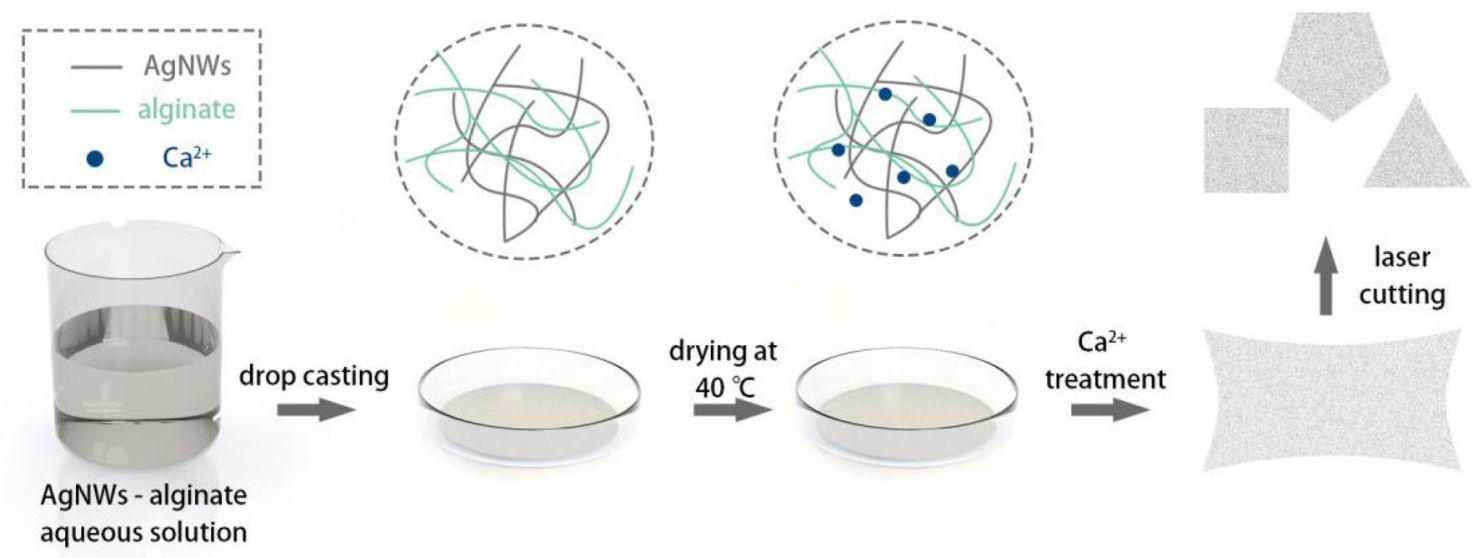

Fig. 11 The schematic diagram of the fabrication process of AgNW-based alginate hydrogels film. The film can be cut into any shapes by laser after forming 
AgNW-based conducting film to replace traditional electrodes. One is the synthesis of higher quality AgNWs, which have a higher aspect ratio and yield a ratio and must be suitable for mass production. The other and most critical point is to develop more appropriate fabrication techniques. The microscopic discontinuities make AgNWs be attached to some carrier for practical applications. Relative to the preparation method, how to integrate AgNWs into the flexible matrix is particularly important.

Although AgNW-based transparent conductive films have surpassed traditional electronic materials in many properties, it is still challenging to replace traditional electronic materials. Although the preparation method of AgNWs has been relatively complete, the high cost of raw material silver makes the cost of printed circuits and other aspects high. Due to the large specific surface area, the AgNW material is very prone to oxidation in the air, resulting in performance degradation. How to treat the surface of the conductive film to prevent oxidation is a problem worthy of consideration. Although graphene is used for surface treatment in some studies, its high cost is still difficult to apply in actual places. The commonly used methods for post-treatment of AgNWbased transparent conductive films are thermal annealing or chemical annealing, which often requires higher temperatures or expensive chemical reagents, which is also an obstacle to the commercialization of AgNWs.

In this review, we discussed the assembly techniques for obtaining the AgNWs conducting film in flexible electronics. In these fabrication techniques, the printing techniques are suitable for detailed printed circuit. The coating techniques are suitable for large-scale preparation of conductive films. The 3D fabrications including are suitable for 3D conducting networks. We believe that with the development of flexible technology, the manufacturing technology of AgNWs conducting film will be further developed, and the commercialization of the AgNW-based flexible conducting film is coming.

\section{Declarations}

Conflict of interest We declare that we have no financial and personal relationships with other people or organizations that can inappropriately influence our work, there is no professional or other personal interest of any nature or kind in any product, service and/or company that could be construed as influencing the position presented in, or the review of, the manuscript entitled, "Recent Progress for Silver Nanowires Conducting Film for Flexible Electronics".

\section{References}

1. Wang, Y., Jiang, D., Zhang, L., Li, B., Sun, C., Yan, H., Wu, Z., Liu, H., Zhang, J., Fan, J., Hou, H., Ding, T., Guo, Z.:
Hydrogen bonding derived self-healing polymer composites reinforced with amidation carbon fibers. Nanotechnology 31(2), 25704 (2019)

2. Nomura, K., Ohta, H., Takagi, A., Kamiya, T., Hirano, M., Hosono, H.: Room-temperature fabrication of transparent flexible thin-film transistors using amorphous oxide semiconductors. Nature 432(7016), 488-492 (2004)

3. Liu, W., Song, M., Kong, B., Cui, Y.: Flexible and stretchable energy storage: recent advances and future perspectives. Adv. Mater. 29(1), 1603436 (2017)

4. Dubal, D.P., Chodankar, N.R., Kim, D., Gomez-Romero, P.: Towards flexible solid-state supercapacitors for smart and wearable electronics. Chem. Soc. Rev. 47(6), 2065-2129 (2018)

5. Dey, A.: Semiconductor metal oxide gas sensors: a review. Mater Sci Eng B-Adv 229, 206-217 (2018)

6. Ong, C.B., Ng, L.Y., Mohammad, A.W.: A review of $\mathrm{ZnO}$ nanoparticles as solar photocatalysts: synthesis, mechanisms and applications. Renew. Sust. Energy Rev. 81(1), 536-551 (2018)

7. Pearton, S.J., Yang, J., Cary, P.H., Ren, F., Kim, J., Tadjer, M.J., Mastro, M.A.: A review of $\mathrm{Ga} 2 \mathrm{O} 3$ materials, processing, and devices. Appl. Phys. Rev. 5, 1 (2018)

8. Patil, G.P., Rondiya, S.R., Vivekan, V., Bagal, S., Shivhare, S., Cross, R.W., Dzade, N.Y., Jadkar, E.R., Chavan, P.G.: Field emission characteristics of double walled $\mathrm{TiO}_{2}$ nanotubes. ES Mater. Manuf. 13, 76-81 (2021)

9. Barma, S.V., Rondiya, S.R., Jadhav, Y.A., Jathar, S.B., Rahane, G.K., Rokade, A., Cross, R.W., Nasane, M.P., Jadkar, V., Dzade, N.Y., Jadkar, E.R.: Structural, optoelectronic, and photoelectrochemical investigation of CdSe nanocrystals prepared by hot injection method. ES Mater. Manuf. 11, 50-56 (2020)

10. Kassou, S., Belaaraj, A., Guionneau, P., Shaltaf, R.: Crystal structure, optical and electronic properties studies on an hybrid multifunctional $\mathrm{MnCl}_{4}$-based material. Adv. Compos. Hybrid Mater. 2(2), 373-380 (2019)

11. Zhang, Y., Yan, Y., Guo, J., Lu, T., Liu, J., Zhou, J., Xu, X.: Superior thermal dissipation in graphene electronic device through novel heat path by electron-phonon coupling. ES Energy Environ. 8, 42-47 (2019)

12. Jia, Y., Ren, P., Wang, J., Fan, C., Liang, E.: Thermal modulation of plasmon induced transparency in graphene metamaterial. ES Energy Environ. 7, 4-11 (2019)

13. Hu, Y., Tang, X., Yang, Y., Zhu, Y.: Near-field radiative thermal modulation by tunneling through graphene sheet. ES Energy Environ. 8, 48-55 (2020)

14. Debenedictis, E.P.: Moore's law: a hard act to follow. Computer 52(12), 114-117 (2019)

15. Simon, P., Gogotsi, Y.: Materials for electrochemical capacitors. Nat. Mater. 7(11), 845-854 (2008)

16. Afroz, S., Afrose, F., Alam, A.K.M.M., Khan, R.A., Alam, M.A.: Synthesis and characterization of polyethylene oxide (PEO)-N, $\mathrm{N}$-dimethylacrylamide (DMA) hydrogel by gamma radiation. Adv. Compos. Hybrid Mater. 2(1), 133-141 (2019)

17. Minami, T.: Transparent conducting oxide semiconductors for transparent electrodes. Semicond Sci. Technol. 20(4), S35-S44 (2005)

18. Hong, C., Shin, J., Ju, B., Kim, K., Park, N., Kim, B., Cheong, W.: Index-matched indium tin oxide electrodes for capacitive touch screen panel applications. J. Nanosci. Nanotechnol. 13(11), 7756-7759 (2013)

19. Wang, S., He, Y., Yang, J., Feng, Y.: Enrichment of indium tin oxide from colour filter glass in waste liquid crystal display panels through flotation. J. Clean Prod. 189, 464-471 (2018)

20. Ji, H.Y., Parida, B., Park, S., Kim, M.J., Chung, S.J., Kim, K.: Enhancement effect of short-circuit currents of Si solar cells with inclusion of indium tin oxide layers on metal-semiconductor interfaces. Jpn. J. Appl. Phys. 54, 10 (2015) 
21. Mana, P.M., Bhujbal, P.K., Pathan, H.M.: Fabrication and characterization of $\mathrm{ZnS}$ based photoelectrochemical solar cell. ES Energy Environ. 12, 77-85 (2021)

22. Wang, C., Xia, K., Wang, H., Liang, X., Yin, Z., Zhang, Y.: Advanced Carbon for Flexible and Wearable Electronics. Adv. Mater. 31(9SI), 1801072 (2019)

23. Kim, J., Campbell, A.S., de Avila, B.E., Wang, J.: Wearable biosensors for healthcare monitoring. Nat. Biotechnol. 37(4), 389-406 (2019)

24. Yu, Z., Bai, Y., Wang, J.H., Li, Y.: Effects of functional additives on structure and properties of polycarbonate-based composites filled with hybrid chopped carbon fiber/graphene nanoplatelet fillers. ES Energy Environ. 12, 66-76 (2021)

25. Gu, J., She, J., Yue, Y.: Micro/nanoscale thermal characterization based on spectroscopy techniques. ES Energy Environ. 9, 15-27 (2020)

26. Desai, S.B., Madhvapathy, S.R., Sachid, A.B., Llinas, J.P., Wang, Q., Ahn, G.H., Pitner, G., Kim, M.J., Bokor, J., Hu, C., Wong, H.S.P., Javey, A.: $\mathrm{MoS}_{2}$ transistors with 1-nanometer gate lengths. Science 354(6308SI), 99-102 (2016)

27. Tian, Y., Yang, X., Nautiyal, A., Zheng, Y., Guo, Q., Luo, J., Zhang, X.: One-step microwave synthesis of $\mathrm{MoS}_{2} / \mathrm{MoO}_{3} @$ graphite nanocomposite as an excellent electrode material for supercapacitors. Adv. Compos. Hybrid Mater. 2(1), 151-161 (2019)

28. Che, B., Zhou, D., Li, H., He, C., Liu, E., Lu, X.: A highly bendable transparent electrode for organic electrochromic devices. Org. Electron. 66, 86-93 (2019)

29. Arico, A.S., Bruce, P., Scrosati, B., Tarascon, J.M., Van Schalkwijk, W.: Nanostructured materials for advanced energy conversion and storage devices. Nat. Mater. 4(5), 366-377 (2005)

30. Splendiani, A., Sun, L., Zhang, Y., Li, T., Kim, J., Chim, C., Galli, G., Wang, F.: Emerging photoluminescence in monolayer $\mathrm{MoS}_{2}$. Nano Lett. 10(4), 1271-1275 (2010)

31. Zhao, S., Wang, H.: An integrated H-type method to measure thermoelectric properties of two-dimensional materials. ES Energy Environ. 9, 59-66 (2020)

32. Han, D., Mei, H., Xiao, S., Cheng, L.: Macroscopic carbon nanotube assembly/silicon carbide matrix composites produced by gas phase route. Adv. Compos. Hybrid Mater. 2(1), 142-150 (2019)

33. Hua, Q., Sun, J., Liu, H., Bao, R., Yu, R., Zhai, J., Pan, C., Wang, Z.L.: Skin-inspired highly stretchable and conformable matrix networks for multifunctional sensing. Nat. Commun. 9, 244 (2018)

34. Huang, H., Han, L., Wang, Y., Yang, Z., Zhu, F., Xu, M.: Tunable thermal-response shape memory bio-polymer hydrogels as body motion sensors. Eng. Sci. 9, 60-67 (2019)

35. Zhao, L., Tallman, T., Lin, G.: Spatial damage characterization in self-sensing materials via neural network-aided electrical impedance tomography: a computational study. ES Mater. Manuf. 12, 78-88 (2021)

36. Dong, Q., Wang, X., Liu, H., Ryu, H., Zhao, J., Li, B., Lei, Y.: Heterogeneous iridium oxide/gold nanocluster for non-enzymatic glucose sensing and pH probing. Eng. Sci. 8, 46-53 (2019)

37. Padvi, M.N., Moholkar, A.V., Prasad, S.R., Prasad, N.R.: A critical review on design and development of gas sensing materials. Eng. Sci. 15, 20-37 (2021)

38. Lu, Y., Yu, G., Wei, X., Zhan, C., Jeon, J., Wang, X., Jeffryes, C., Guo, Z., Wei, S., Wujcik, E.K.: Fabric/multi-walled carbon nanotube sensor for portable on-site copper detection in water. Adv. Compos. Hybrid Mater. 2(4), 711-719 (2019)

39. Wei, H., Li, A., Kong, D., Li, Z., Cui, D., Li, T., Dong, B., Guo, Z.: Polypyrrole/reduced graphene aerogel film for wearable piezoresisitic sensors with high sensing performances. Adv. Compos. Hybrid Mater. 4(1), 86-95 (2021)
40. Jayachandiran, J., Arivanandhan, M., Padmaraj, O., Jayavel, R., Nedumaran, D.: Investigation on ozone-sensing characteristics of surface sensitive hybrid $\mathrm{rGO} / \mathrm{WO}_{3}$ nanocomposite films at ambient temperature. Adv. Compos. Hybrid Mater. 3(1), 16-30 (2020)

41. Patil, S.S., Bhat, T.S., Teli, A.M., Beknalkar, S.A., Dhavale, S.B., Faras, M.M., Karanjkar, M.M., Patil, P.S.: Hybrid solid state supercapacitors (HSSC\&rsquo;s) for high energy \& power density: an overview. Eng. Sci. 12, 38-51 (2020)

42. Cai, J., Xu, W., Liu, Y., Zhu, Z., Liu, G., Ding, W., Wang, G., Wang, H., Luo, Y.: Robust construction of flexible bacterial Cellulose@ $\mathrm{Ni}(\mathrm{OH})_{2}$ paper: toward high capacitance and sensitive $\mathrm{H} 2 \mathrm{O} 2$ detection. Eng. Sci. 5, 21-29 (2019)

43. Nie, R., Wang, Q., Sun, P., Wang, R., Yuan, Q., Wang, X.: Pulsed laser deposition of $\mathrm{NiSe}_{2}$ film on carbon nanotubes for high-performance supercapacitor. Eng. Sci. 6, 22-29 (2019)

44. Dong, H., Li, Y., Chai, H., Cao, Y., Chen, X.: Hydrothermal synthesis of $\mathrm{CuCo}_{2} \mathrm{~S}_{4}$ nano-structure and $\mathrm{N}$-doped graphene for high-performance aqueous asymmetric supercapacitors. ES Energy Environ. 4, 19-26 (2019)

45. Sayyed, S.G., Mahadik, M.A., Shaikh, A.V., Jang, J.S., Pathan, H.M.: Nano-metal oxide based supercapacitor via electrochemical deposition. ES Energy Environ. 3, 25-44 (2019)

46. Rehman, S.U., Ahmed, R., Ma, K., Xu, S., Tao, T., Aslam, M.A., Amir, M., Wang, J.: Composite of strip-shaped ZIF-67 with polypyrrole: a conductive polymer-MOF electrode system for stable and high specific capacitance. Eng. Sci. 13, 71-78 (2021)

47. Li, X., Zhao, W., Yin, R., Huang, X., Qian, L.: A highly porous polyaniline-graphene composite used for electrochemical supercapacitors. Eng. Sci. 3, 89-95 (2018)

48. Wang, X., Zeng, X., Cao, D.: Biomass-derived nitrogen-doped porous carbons (NPC) and NPC/polyaniline composites as high performance supercapacitor materials. Eng. Sci. 1, 55-63 (2018)

49. Li, G., Ji, Y., Zuo, D., Xu, J., Zhang, H.: Carbon electrodes with double conductive networks for high-performance electrical double-layer capacitors. Adv. Compos. Hybrid Mater. 2(3), 456-461 (2019)

50. Xiao, L., Qi, H., Qu, K., Shi, C., Cheng, Y., Sun, Z., Yuan, B., Huang, Z., Pan, D., Guo, Z.: Layer-by-layer assembled freestanding and flexible nanocellulose/porous $\mathrm{Co}_{3} \mathrm{O}_{4}$ polyhedron hybrid film as supercapacitor electrodes. Adv. Compos. Hybrid Mater. 4(2), 306-316 (2021)

51. Koo, J.H., Kim, D.C., Shim, H.J., Kim, T., Kim, D.: Flexible and stretchable smart display: materials, fabrication, device design, and system integration. Adv. Funct. Mater. 28(35), 1801834 (2018)

52. Kim, Y., Chortos, A., Xu, W., Liu, Y., Oh, J.Y., Son, D., Kang, J., Foudeh, A.M., Zhu, C., Lee, Y., Niu, S., Liu, J., Pfattner, R., Bao, Z., Lee, T.: A bioinspired flexible organic artificial afferent nerve. Science 360(6392), 998 (2018)

53. Son, D., Kang, J., Vardoulis, O., Kim, Y., Matsuhisa, N., Oh, J.Y., To, J.W.F., Mun, J., Katsumata, T., Liu, Y., Mcguire, A.F., Krason, M., Molina-Lopez, F., Ham, J., Kraft, U., Lee, Y., Yun, Y., Tok, J.B., Bao, Z.: An integrated self-healable electronic skin system fabricated via dynamic reconstruction of a nanostructured conducting network. Nat. Nanotechnol. 13(11), 1057 (2018)

54. Issa, T.T., Mohammed, A.A., Abaas, Z.E., Shokr, F.S.: Development of some electrical properties of composites polymer based on nano copper particles. Acta. Phys. Pol a 134(1SI), 457-459 (2018)

55. Xin, Y., Takeuchi, Y., Hattori, M., Shirai, T.: Enhanced electrical conductivity of alumina/nano-carbon ceramic composite via iodine impregnation of gel-casted alumina body and reductive sintering. J Eur Ceram Soc 39(14), 4440-4444 (2019) 
56. Chen, J., Yan, L., Song, W., Xu, D.: Thermal and electrical properties of carbon nanotube-based epoxy composite materials. Mater Res Express 5(6), 065051 (2018)

57. Jamesh, M.: Recent advances on flexible electrodes for Na-ion batteries and Li-S batteries. J. Energy Chem. 32, 15-44 (2019)

58. Fan, F., Tian, Z., Wang, Z.L.: Flexible triboelectric generator! Nano Energy 1(2), 328-334 (2012)

59. Choi, D.Y., Kim, M.H., Oh, Y.S., Jung, S., Jung, J.H., Sung, H.J., Lee, H.W., Lee, H.M.: Highly stretchable, hysteresis-free ionic liquid-based strain sensor for precise human motion monitoring. Acs Appl. Mater. Inter. 9(2), 1770-1780 (2017)

60. De Volder, M.F.L., Tawfick, S.H., Baughman, R.H., Hart, A.J.: Carbon nanotubes: present and future commercial applications. Science 339(6119), 535-539 (2013)

61. Sun, H., Xu, Z., Gao, C.: Multifunctional, ultra-flyweight, synergistically assembled carbon aerogels. Adv. Mater. 25(18), 2554-2560 (2013)

62. Yang, Y.L., Gupta, M.C.: Novel carbon nanotube-polystyrene foam composites for electromagnetic interference shielding. Nano Lett. 5(11), 2131-2134 (2005)

63. Fan, F.R., Tang, W., Wang, Z.L.: Flexible nanogenerators for energy harvesting and self-powered electronics. Adv. Mater. 28(22SI), 4283-4305 (2016)

64. Zeng, W., Shu, L., Li, Q., Chen, S., Wang, F., Tao, X.: Fabrication, devices, and applications. Adv. Mater. 26(31), 5310-5336 (2014)

65. Allard, S., Forster, M., Souharce, B., Thiem, H., Scherf, U.: Organic semiconductors for solution-processable field-effect transistors (OFETs). Angew Chem Int Edit 47(22), 4070-4098 (2008)

66. Prabhu, P., Iqbal, S.M., Balaji, A., Karthikeyan, B.: Experimental investigation of mechanical and machining parameters of hybrid nanoclay glass fiber-reinforced polyester composites. Adv Compos Hybrid Mater 2(1), 93-101 (2019)

67. Bae, S., Kim, H., Lee, Y., Xu, X., Park, J., Zheng, Y., Balakrishnan, J., Lei, T., Kim, H.R., Song, Y.I., Kim, Y., Kim, K.S., Ozyilmaz, B., Ahn, J., Hong, B.H., Iijima, S.: Roll-to-roll production of 30-inch graphene films for transparent electrodes. Nat. Nanotechnol. 5(8), 574-578 (2010)

68. Kim, K.S., Zhao, Y., Jang, H., Lee, S.Y., Kim, J.M., Kim, K.S., Ahn, J., Kim, P., Choi, J., Hong, B.H.: Large-scale pattern growth of graphene films for stretchable transparent electrodes. Nature 457(7230), 706-710 (2009)

69. Chen, Y., Guo, Z., Das, R., Jiang, Q.: Starch-based carbon nanotubes and graphene: preparation properties and applications. ES Food Agrofor. 2, 13-21 (2020)

70. Liu, H., Mao, Y.: Graphene oxide-based nanomaterials for uranium adsorptive uptake. ES Mater. Manuf. 13, 3-22 (2021)

71. Yang, H., Li, Q., Wang, Z., Wu, H., Wu, Y., Hou, P., Cheng, X.: Effect of graphene on microstructure and mechanical properties of $\mathrm{Si}_{3} \mathrm{~N}_{4} / \mathrm{SiC}$ ceramics. ES Mater. Manuf. 12, 29-34 (2021)

72. Bustero, I., Gaztelumendi, I., Obieta, I., Asun Mendizabal, M., Zurutuza, A., Ortega, A., Alonso, B.: Free-standing graphene films embedded in epoxy resin with enhanced thermal properties. Adv. Compos. Hybrid Mater. 3(1), 31-40 (2020)

73. Singh, N., Jana, S., Singh, G.P., Dey, R.K.: Graphene-supported $\mathrm{TiO}_{2}$ : study of promotion of charge carrier in photocatalytic water splitting and methylene blue dye degradation. Adv. Compos. Hybrid Mater. 3(1), 127-140 (2020)

74. Madhusudhana, A.M., Mohana, K.N.S., Hegde, M.B., Nayak, S.R., Rajitha, K., Swamy, N.K.: Functionalized graphene oxideepoxy phenolic novolac nanocomposite: an efficient anticorrosion coating on mild steel in saline medium. Adv. Compos. Hybrid Mater. 3(2), 141-155 (2020)

75. Lin, C., Hu, L., Cheng, C., Sun, K., Guo, X., Shao, Q., Li, J., Wang, N., Guo, Z.: Nano-TiNb ${ }_{2} \mathrm{O}_{7}$ /carbon nanotubes composite anode for enhanced lithium-ion storage. Electrochim Acta 260, 65-72 (2018)

76. Cheng, Y., Zhao, S., Johannessen, B., Veder, J., Saunders, M., Rowles, M.R., Cheng, M., Liu, C., Chisholm, M.F., De Marco, R., Cheng, H., Yang, S., Jiang, S.P.: Atomically dispersed transition metals on carbon nanotubes with ultrahigh loading for selective electrochemical carbon dioxide reduction. Adv. Mater. 30(13), 1706287 (2018)

77. Saba, F., Sajjadi, S.A., Heydari, S., Haddad-Sabzevar, M., Salehi, J., Babayi, H.: A novel approach to the uniformly distributed carbon nanotubes with intact structure in aluminum matrix composite. Adv. Compos. Hybrid Mater. 2(3), 540-548 (2019)

78. Wang, Z., Li, X., Wang, L., Li, Y., Qin, J., Xie, P., Qu, Y., Sun, K., Fan, R.: Flexible multi-walled carbon nanotubes/polydimethylsiloxane membranous composites toward high-permittivity performance. Adv. Compos. Hybrid Mater. 3(1), 1-7 (2020)

79. Mirabootalebi, S.O.: A new method for preparing buckypaper by pressing a mixture of multi-walled carbon nanotubes and amorphous carbon. Adv. Compos. Hybrid Mater. 3(3), 336-343 (2020)

80. Nair, R.R., Blake, P., Grigorenko, A.N., Novoselov, K.S., Booth, T.J., Stauber, T., Peres, N.M.R., Geim, A.K.: Fine structure constant defines visual transparency of graphene. Science 320(5881), 1308 (2008)

81. Zhang, B., Li, H., Xu, H., Zhao, M., Xiong, C., Liu, C., Wu, K.: Absorption and slow-light analysis based on tunable plasmoninduced transparency in patterned graphene metamaterial. Opt Expr. 27(3), 3598-3608 (2019)

82. Li, X., Sun, C., Cao, W., Hu, C., Zhao, Y.: Comparative adsorption of remazol brilliant blue $\mathrm{R}$ and copper in aqueous solutions by carbon nanotubes with different levels of carboxyl group and specific surface area. Mater. Res. Express 6(10), 1050e2 (2019)

83. Xu, N., Zhang, Y., Zhang, T., Liu, Y., Qiao, J.: Efficient quantum dots anchored nanocomposite for highly active ORR/OER electrocatalyst of advanced metal-air batteries. Nano Energy 57, 176-185 (2019)

84. Li, Y., Fu, Y., Liu, W., Song, Y., Wang, L.: Hollow $\mathrm{Co}^{-} \mathrm{Co}_{3} \mathrm{O}_{4} @$ CNTs derived from ZIF-67 for lithium ion batteries. J. Alloy. Compd. 784, 439-446 (2019)

85. Bai, Y., Shen, B., Zhang, S., Zhu, Z., Sun, S., Gao, J., Li, B., Wang, Y., Zhang, R., Wei, F.: Storage of mechanical energy based on carbon nanotubes with high energy density and power density. Adv. Mater. 31(9SI), 1800680 (2019)

86. Hu, S., Xu, Y., Wang, J., Zhang, P., Guo, J.: Modification effects of carbon nanotube dispersion on the mechanical properties, pore structure, and microstructure of cement mortar. Materials 13(5), $1101(2020)$

87. Mei, H., Zhao, Y., Han, D., Ji, T., Xu, L., Cheng, L., Dassios, K.G.: Depositing CNTs on the interface and surface of $\mathrm{C} / \mathrm{PyC} /$ $\mathrm{SiCs}$ for tunable mechanical and electromagnetic properties. Ceram Int. 45(17B), 23411-23417 (2019)

88. Yang, Y., Gao, W.: Wearable and flexible electronics for continuous molecular monitoring. Chem. Soc. Rev. 48(6), 1465-1491 (2019)

89. Mohan, V.B., Lau, K., Hui, D., Bhattacharyya, D.: Graphenebased materials and their composites: a review on production, applications and product limitations. Compos. Part B-Eng. 142, 200-220 (2018)

90. Li, Y., Zhou, B., Zheng, G., Liu, X., Li, T., Yan, C., Cheng, C., Dai, K., Liu, C., Shen, C., Guo, Z.: Continuously prepared highly conductive and stretchable SWNT/MWNT synergistically composited electrospun thermoplastic polyurethane yarns for wearable sensing. J. Mater. Chem. C 6(9), 2258-2269 (2018)

91. Xu, Y., Bai, H., Lu, G., Li, C., Shi, G.: Flexible graphene films via the filtration of water-soluble noncovalent functionalized graphene sheets. J. Am. Chem. Soc. 130(18), 5856 (2008) 
92. Zhang, R., Chen, X., Shen, X., Zhang, X., Chen, X., Cheng, X., Yan, C., Zhao, C., Zhang, Q.: Coralloid carbon fiber-based composite lithium anode for robust lithium metal batteries. Joule 2(4), 764-777 (2018)

93. Yao, L., Wu, Q., Zhang, P., Zhang, J., Wang, D., Li, Y., Ren, X., Mi, H., Deng, L., Zheng, Z.: Scalable 2D hierarchical porous carbon nanosheets for flexible supercapacitors with ultrahigh energy density. Adv. Mater. 30(11), 1706054 (2018)

94. Zhong, Y., Xia, X., Deng, S., Zhan, J., Fang, R., Xia, Y., Wang, X., Zhang, Q., Tu, J.: Popcorn inspired porous macrocellular carbon: rapid puffing fabrication from rice and its applications in lithium-sulfur batteries. Adv. Energy Mater. 8(1), 1701110 (2018)

95. Lu, Y., Yu, L., Lou, X.W.D.: Nanostructured conversion-type anode materials for advanced lithium-ion batteries. Chem-Us 4(5), 972-996 (2018)

96. Ham, J., Lee, J.: ITO Breakers: highly transparent conducting polymer/metal/dielectric $(\mathrm{P} / \mathrm{M} / \mathrm{D})$ films for organic solar cells. Adv. Energy Mater. 4(15), 1400539 (2014)

97. Ovid'Ko, I.A., Valiev, R.Z., Zhu, Y.T.: Review on superior strength and enhanced ductility of metallic nanomaterials. Prog. Mater. Sci. 94, 462-540 (2018)

98. Cao, Y., Ni, S., Liao, X., Song, M., Zhu, Y.: Structural evolutions of metallic materials processed by severe plastic deformation. Mat. Sci. Eng. R 133, 1-59 (2018)

99. Alawi, O.A., Sidik, N.A.C., Xian, H.W., Kean, T.H., Kazi, S.N.: Thermal conductivity and viscosity models of metallic oxides nanofluids. Int. J. Heat Mass Tran. 116, 1314-1325 (2018)

100. Zhou, G., Shan, Y., Hu, Y., Xu, X., Long, L., Zhang, J., Dai, J., Guo, J., Shen, J., Li, S., Liu, L., Wu, X.: Half-metallic carbon nitride nanosheets with micro grid mode resonance structure for efficient photocatalytic hydrogen evolution. Nat. Commun. 9, $3366(2018)$

101. Xie, F., Liu, T., Xie, L., Sun, X., Luo, Y.: Metallic nickel nitride nanosheet: An efficient catalyst electrode for sensitive and selective non-enzymatic glucose sensing. Sensor Actuat. B-Chem. 255(3), 2794-2799 (2018)

102. Wei, Q., Xiong, F., Tan, S., Huang, L., Lan, E.H., Dunn, B., Mai, L.: Porous one-dimensional nanomaterials: design, fabrication and applications in electrochemical energy storage. Adv. Mater. 29(20), 1602300 (2017)

103. Ge, M., Li, Q., Cao, C., Huang, J., Li, S., Zhang, S., Chen, Z., Zhang, K., Al-Deyab, S.S., Lai, Y.: One-dimensional $\mathrm{TiO}_{2}$ nanotube photocatalysts for solar water splitting. Adv. Sci. 4(1), 1600152 (2017)

104. Zhang, G., Xiao, X., Li, B., Gu, P., Xue, H., Pang, H.: Transition metal oxides with one-dimensional/one-dimensional-analogue nanostructures for advanced supercapacitors. J. Mater. Chem. 5(18), 8155-8186 (2017)

105. Wang, C., Kaneti, Y.V., Bando, Y., Lin, J., Liu, C., Li, J., Yamauchi, Y.: Metal-organic framework-derived one-dimensional porous or hollow carbon-based nanofibers for energy storage and conversion. Mater. Horiz. 5(3), 394-407 (2018)

106. Gong, S., Cheng, W.: One-dimensional nanomaterials for soft electronics. Adv. Electron Mater. 3(3), 1600314 (2017)

107. Tian, W., Hu, H., Wang, Y., Li, P., Liu, J., Liu, J., Wang, X., Xu, X., Li, Z., Zhao, Q., Ning, H., Wu, W., Wu, M.: Metal-organic frameworks mediated synthesis of one-dimensional molybdenum-based/carbon composites for enhanced lithium storage. ACS Nano 12(2), 1990-2000 (2018)

108. Seok, I., Al-Hossain, A.A., Waliullah, M., Ryu, J.E.: Fabrication of nano-patterned arrays using pulsed light technique. Eng. Sci. 7, 59-64 (2019)

109. Ul-Islam, M.U., Ali, J., Khan, W., Haider, A., Shah, N., Ahmad, M.W., Ullah, M.W., Yang, G.: Fast 4-nitrophenol reduction using gelatin hydrogel containing silver nanoparticles. Eng. Sci 8, 19-24 (2019)

110. Yu, J., Sun, L.: Facile one-pot synthesis of silver nanoparticles supported on \&alpha;-zirconium phosphate single-layer nanosheets. ES Mater Manuf 5, 24-28 (2019)

111. Matveev, K.A., Ristivojevic, Z.: Thermal conductivity of the degenerate one-dimensional Fermi gas. Phys Rev B 99(15), 155428 (2019)

112. Kandemir, A., Ozden, A., Cagin, T., Sevik, C.: Thermal conductivity engineering of bulk and one-dimensional Si-Ge nanoarchitectures. Sci. Technol. Adv. Mat. 18(1), 187-196 (2017)

113. Chen, C., Yin, D., Inoue, K., Lichtenberg, F., Ma, X., Ikuhara, Y., Bednorz, J.G.: Atomic-scale origin of the quasi-one-dimensional metallic conductivity in strontium niobates with perovskite-related layered structures. ACS Nano 11(12), 12519-12525 (2017)

114. Arkhipkin, V.G., Myslivets, S.A.: Effect of electromagnetically induced transparency on the spectrum of defect modes in a onedimensional photonic crystal. Quantum Electron 39(2), 157-162 (2009)

115. Zhang, Y., Dong, G., Zou, B.: Disorder-induced transparency in a one-dimensional waveguide side coupled with optical cavities. J. Appl. Phys. 115(17), 173105 (2014)

116. Kraiski, A.A., Kraiski, A.V.: On the properties of transparency windows near the band gap edge of one-dimensional photonic crystals. B Lebedev Phys. Inst. 45(2), 56-62 (2018)

117. Ibrayev, N., Omarova, G., Seliverstova, E., Alex, A., Ishchenko, E., Nuraje, N.: Plasmonic effect of Ag nanoparticles on polymethine dyes sensitized titanium dioxide. Eng. Sci. 14, 69-77 (2021)

118. Duan, R.: Global strong solution for initial-boundary value problem of one-dimensional compressible micropolar fluids with density dependent viscosity and temperature dependent heat conductivity. Nonlinear Anal. Real 42, 71-92 (2018)

119. Lima, L.S.: Thermal transport in the one-dimensional spin-1/2 anisotropic antiferromagnet in a staggered magnetic field. J. Magn. Magn. Mater. 323(8), 1064-1067 (2011)

120. Lin, H., Liu, X., Kou, A., Xu, S., Dong, H.: One-dimensional thermal characterization at the micro/nanoscale: review of the TET technique. Int. J. Thermophys. 40, 12 (2019)

121. Yu, Y., Lu, M., Chen, M.H., Wang, L.S., Bu, Z.X., Song, G., Sun, L.: Modeling of dynamic mechanical properties of polymer composites reinforced by one dimensional nanofillers. J. Appl. Phys. 120(17), 175103 (2016)

122. Kou, L., Liu, Y., Zhang, C., Shao, L., Tian, Z., Deng, Z., Gao, C.: A mini review on nanocarbon-based 1D macroscopic fibers: assembly strategies and mechanical properties. Nano-Micro Lett. 9(4), 51 (2017)

123. Hu, L., Kim, H.S., Lee, J., Peumans, P., Cui, Y.: Scalable coating and properties of transparent, flexible silver nanowire electrodes. ACS Nano 4(5), 2955-2963 (2010)

124. Wang, X., Zhi, L., Müllen, K.: Transparent, conductive graphene electrodes for dye-sensitized solar cells. Nano Lett. 8(1), 323327 (2008)

125. Chen, Z., Ren, W., Gao, L., Liu, B., Pei, S., Cheng, H.: Threedimensional flexible and conductive interconnected graphene networks grown by chemical vapour deposition. Nat. Mater. 10(6), 424-428 (2011)

126. Li, X., Zhu, Y., Cai, W., Borysiak, M., Han, B., Chen, D., Piner, R.D., Colombo, L., Ruoff, R.S.: Transfer of Large-Area Graphene Films for High-Performance Transparent Conductive Electrodes. Nano Lett 9(12), 4359-4363 (2009)

127. Hu, L., Hecht, D.S., Grüner, G.: Percolation in Transparent and Conducting Carbon Nanotube Networks. Nano Lett 4(12), 2513 2517 (2004) 
128. Zhang, D., Ryu, K., Liu, X., Polikarpov, E., Ly, J., Tompson, M.E., Zhou, C.: Transparent, conductive, and flexible carbon nanotube films and their application in organic light-emitting diodes. Nano Lett. 6(9), 1880-1886 (2006)

129. Wang, H., Liao, S., Bai, X., Liu, Z., Fang, M., Liu, T., Wang, N., Wu, H.: Highly flexible indium tin oxide nanofiber transparent electrodes by blow spinning. Acs Appl. Mater. Inter. 8(48), 32661-32666 (2016)

130. Liu, C., Lin, Y., Dong, Y., Wu, Y., Bao, Y., Yan, H., Ma, J.: Fabrication and investigation on $\mathrm{Ag}$ nanowires/ $/ \mathrm{TiO}_{2}$ nanosheets/graphene hybrid nanocomposite and its water treatment performance. Adv. Compos. Hybrid Mater. 3(3), 402-414 (2020)

131. Liu, L., He, C., Li, J., Guo, J., Yang, D., Wei, J.: Green synthesis of silver nanowires via ultraviolet irradiation catalyzed by phosphomolybdic acid and their antibacterial properties. New J. Chem. 37(7), 2179-2185 (2013)

132. Xu, J., Hu, J., Peng, C., Liu, H., Hu, Y.: A simple approach to the synthesis of silver nanowires by hydrothermal process in the presence of gemini surfactant. J. Colloid Inter. Sci. 298(2), 689-693 (2006)

133. Liu, R., Wong, F., Duan, W., Sen, A.: Synthesis and characterization of silver halide nanowires. Polyhedron 84(SI), 192-196 (2014)

134. Zhou, Y., Yu, S.H., Wang, C.Y., Li, X.G., Zhu, Y.R., Chen, Z.Y.: A Novel Ultraviolet Irradiation Photoreduction Technique for the Preparation of Single-Crystal Ag Nanorods and Ag Dendrites. Adv Mater 11, 850-852 (1999)

135. Li, W., Zhang, H., Shi, S., Xu, J., Qin, X., He, Q., Yang, K., Dai, W., Liu, G., Zhou, Q., Yu, H., Silva, S.R.P., Fahlman, M.: Recent progress in silver nanowire networks for flexible organic electronics. J. Mater. Chem. C. 8(14), 4636-4674 (2020)

136. Kwon, J., Suh, Y.D., Lee, J., Lee, P., Han, S., Hong, S., Yeo, J., Lee, H., Ko, S.H.: Recent progress in silver nanowire based flexible/wearable optoelectronics. J. Mater. Chem. C 6(28), 7445-7461 (2018)

137. Chen, T., Yang, H., Bai, S., Zhang, Y., Guo, X.: Facile preparation of patterned silver electrodes with high conductivity, flatness and adjustable work function by laser direct writing followed by transfer process. Appl Surf Sci 530, 147237 (2020)

138. Mathieu-Pennober, T., Foldyna, M., Zhang, S., Julien, F.H., Schneider, N., Tchernycheva, M.: Improvement of carrier collection in $\mathrm{Si} / \mathrm{a}-\mathrm{Si}$ : $\mathrm{H}$ nanowire solar cells by using hybrid ITO/silver nanowires contacts. Nanotechnology 31(43), 435408 (2020)

139. Xiao, D., Navik, R., Tan, H., Gai, Y., Zhao, Y.: Sorting purified silver nanowires using supercritical carbon dioxide elutriation coupled with membrane for fabricating flexible and transparent conductive electrodes. J. Supercrit. Fluid 164, 104915 (2020)

140. Liang, T., Shi, P., Su, S., Zhang, X., Dai, X.: Near-perfect healing natures of silver five-fold twinned nanowire. Comp. Mater. Sci. 183, 109796 (2020)

141. Li, W., Yarali, E., Bakytbekov, A., Anthopoulos, T.D., Shamim, A.: Highly transparent and conductive electrodes enabled by scalable printing-and-sintering of silver nanowires. Nanotechnology 31(39), 395201 (2020)

142. Chung, W., Jang, Y., Hwang, Y., Kim, S., Kim, H.: The surface plasmonic welding of silver nanowires via intense pulsed light irradiation combined with NIR for flexible transparent conductive films. Nanoscale 12(34), 17725-17737 (2020)

143. Zhang, L., Li, H., Lai, X., Gao, T., Zeng, X.: Three-Dimensional Binary-Conductive-Network Silver Nanowires@Thiolated Graphene Foam Based Room-Temperature Self-Healable Strain Sensor for Human Motion Detection. Acs Appl Mater Inter 12(39), 44360-44370 (2020)

144. Atkinson, J., Goldthorpe, I.A.: Near-infrared properties of silver nanowire networks. Nanotechnology 31(36), 365201 (2020)
145. Kinner, L., List-Kratochvil, E.J.W., Dimopoulos, T.: Gentle plasma process for embedded silver-nanowire flexible transparent electrodes on temperature-sensitive polymer substrates. Nanotechnology 31(36), 365303 (2020)

146. Zhao, Y., Fitzgerald, M.L., Tao, Y., Pan, Z., Sauti, G., Xu, D., $\mathrm{Xu}, \mathrm{Y} ., \mathrm{Li}, \mathrm{D} .:$ Electrical and thermal transport through silver nanowires and their contacts: effects of elastic stiffening. Nano Lett 20(10), 7389-7396 (2020)

147. Bai, S., Guo, X., Chen, T., Zhang, Y., Yang, H.: Solution process fabrication of silver nanowire composite transparent conductive films with tunable work function. Thin Solid Films 709, 138096 (2020)

148. Helgason, R., Campigotto, A., Lai, Y.: The development of a pressure sensor using a technique for patterning silver nanowires on 3-dimensional curved PDMS membranes. J. Micromech. Microeng. 30(9), 095013 (2020)

149. Wu, S., Yao, S., Liu, Y., Hu, X., Huang, H.H., Zhu, Y.: Buckledelamination-enabled stretchable silver nanowire conductors. Acs Appl. Mater. Inter. 12(37), 41696-41703 (2020)

150. Zhang, S., Liu, X., Lin, T., He, P.: A method to fabricate uniform silver nanowires transparent electrode using Meyer rod coating and dynamic heating. J. Mater. Sci. 30(20), 1870218709 (2019)

151. Song, Y., Chen, J., Wu, J., Zhang, T.: Applications of silver nanowires on transparent conducting film and electrode of electrochemical capacitor. J. Nanomater. 2014, 193201 (2014)

152. Zhang, Y., Bai, S., Chen, T., Yang, H., Guo, X.: Facile preparation of flexible and highly stable graphene oxide-silver nanowire hybrid transparent conductive electrode. Mater. Res. Expr. 7(1), 16413 (2020)

153. Rahane, G.K., Jathar, S.B., Rondiya, S.R., Jadhav, Y.A., Barma, S.V., Rokade, A., Cross, R.W., Nasane, M.P., Jadkar, V., Dzade, N.Y., Jadkar, E.R.: Photoelectrochemical investigation on the cadmium sulfide (CdS) thin films prepared using spin coating technique. ES Mater. Manuf. 11, 57-64 (2020)

154. Lee, W., Kihm, K.D., Lee, W., Won, P., Han, S., Lim, G., Pyun, K.R., Ko, S.H.: Boosted thermal conductance of polycrystalline graphene by spin-coated silver nanowires. Int. J. Heat Mass Trans. 134, 547-553 (2019)

155. Lang, K., Klein, M., Domann, G., Loebmann, P.: Transparent conductive organic-inorganic hybrid composites based on $\mathrm{Ag}$ nanowires. J. Sol-Gel Sci. Technol. 96(1), 121-129 (2020)

156. Ricciardulli, A.G., Yang, S., Wetzelaer, G.A.H., Feng, X., Blom, P.W.M.: Hybrid silver nanowire and graphene-based solution-processed transparent electrode for organic optoelectronics. Adv. Funct. Mater. 28(14), 1706010 (2018)

157. Langley, D.P., Lagrange, M., Giusti, G., Jimenez, C., Brechet, Y., Nguyen, N.D., Bellet, D.: Metallic nanowire networks: effects of thermal annealing on electrical resistance. Nanoscale 6(22), 13535-13543 (2014)

158. Tokuno, T., Nogi, M., Karakawa, M., Jiu, J., Thi, T.N., Aso, Y., Suganuma, K.: Fabrication of silver nanowire transparent electrodes at room temperature. Nano Res. 4(12), 1215-1222 (2011)

159. Park, J.H., Hwang, G., Kim, S., Seo, J., Park, H., Yu, K., Kim, T., Lee, K.J.: Flash-induced self-limited plasmonic welding of silver nanowire network for transparent flexible energy harvester. Adv. Mater. 29(5), 1603473 (2017)

160. Jiang, D., Wang, Y., Li, B., Sun, C., Wu, Z., Yan, H., Xing, L., Qi, S., Li, Y., Liu, H., Xie, W., Wang, X., Ding, T., Guo, Z.: Flexible sandwich structural strain sensor based on silver nanowires decorated with self-healing substrate. Macromol. Mater. Eng. 304(7), 1900074 (2019)

161. Cui, Z.: Printing practice for the fabrication of flexible and stretchable electronics. Sci. China Technol. Sci. 62(2), 224-232 (2019) 
162. Zhang, N., Guo, Q., Yang, J.: The development of digital printing technologies for flexible electronics devices. Scientia Sinica Physica, Mechanica Astronomica 46(4), 44608 (2016)

163. Wang, J., Liu, Y., Fan, Z., Wang, W., Wang, B., Guo, Z.: Inkbased 3D printing technologies for graphene-based materials: a review. Adv. Compos. Hybrid Mater. 2(1), 1-33 (2019)

164. Xiao, Y., Hong, Z., Zhao, G.C.H., Liang, R., Lucas, P., Hao, Q.: Thermal studies of three-dimensional printing using pulsed laser heating. ES Mater. Manuf. 1, 21-26 (2018)

165. Xia, X., Xu, X., Lin, C., Yang, Y., Zeng, L., Zheng, Y., Wu, X., Li, W., Xiao, L., Qian, Q., Chen, Q.: Microalgal-immobilized biocomposite scaffold fabricated by fused deposition modeling, 3D printing technology for dyes removal. ES Mater. Manuf. 7, 40-50 (2020)

166. Mei, H., Ali, Z., Ali, I., Cheng, L.: Tailoring strength and modulus by $3 \mathrm{D}$ printing different continuous fibers and filled structures into composites. Adv. Compos. Hybrid Mater. 2(2), 312-319 (2019)

167. Eda, G., Fanchini, G., Chhowalla, M.: Large-area ultrathin films of reduced graphene oxide as a transparent and flexible electronic material. Nat. Nanotechnol. 3(5), 270-274 (2008)

168. Tobjork, D., Osterbacka, R.: Paper electronics. Adv. Mater. 23(17), 1935-1961 (2011)

169. Zhu, W., Chen, Y., Zhang, Z., Tian, X., Li, D.: In-situ packaging 3D printing process for stretchable flexible circuits. J. Mech. Eng. 55(15), 64-70 (2019)

170. Correia, V., Mitra, K.Y., Castro, H., Rocha, J.G., Sowade, E., Baumann, R.R., Lanceros-Mendez, S.: Design and fabrication of multilayer inkjet-printed passive components for printed electronics circuit development. J. Manuf. Process 31, 364-371 (2018)

171. Briseno, A.L., Mannsfeld, S.C.B., Ling, M.M., Liu, S., Tseng, R.J., Reese, C., Roberts, M.E., Yang, Y., Wudl, F., Bao, Z.: Patterning organic single-crystal transistor arrays. Nature 444(7121), 913-917 (2006)

172. Yan, H., Chen, Z., Zheng, Y., Newman, C., Quinn, J.R., Dotz, F., Kastler, M., Facchetti, A.: A high-mobility electron-transporting polymer for printed transistors. Nature 457(7230), 671-679 (2009)

173. Gao, L., Zhu, C., Li, L., Zhang, C., Liu, J., Yu, H., Huang, W.: All paper-based flexible and wearable piezoresistive pressure sensor. Acs Appl. Mater. Inter. 11(28), 25034-25042 (2019)

174. Cui, Z., Han, Y., Huang, Q., Dong, J., Zhu, Y.: Electrohydrodynamic printing of silver nanowires for flexible and stretchable electronics. Nanoscale 10(15), 6806-6811 (2018)

175. Janczak, D., Zych, M., Raczynski, T., Dybowska-Sarapuk, L., Peplowski, A., Krzeminski, J., Sosna-Glebska, A., Znajdek, K., Sibinski, M., Jakubowska, M.: Stretchable and washable electroluminescent display screen-printed on textile. Nanomater. Basel 9(9), 1276 (2019)

176. Zhao, C., Zhou, Y., Gu, S., Cao, S., Wang, J., Zhang, M., Wu, Y., Kong, D.: Fully screen-printed, multicolor, and stretchable electroluminescent displays for epidermal electronics. Acs Appl. Mater. Inter. 12(42), 47902-47910 (2020)

177. Pei, W., Guo, D., Geng, Z., Chen, H.: Printed sensor technology. Mater. China 33(3), 172-179 (2014)

178. Muth, J.T., Vogt, D.M., Truby, R.L., Menguec, Y., Kolesky, D.B., Wood, R.J., Lewis, J.A.: Embedded 3D printing of strain sensors within highly stretchable elastomers. Adv. Mater. 26(36), 6307-6312 (2014)

179. Nam, J., Lee, Y., Choi, W., Kim, C.S., Kim, H., Kim, J., Kim, D., Jo, S.: Transfer printed flexible and stretchable thin film solar cells using a water-soluble sacrificial layer. Adv. Energy Mater. 6(21), 1601269 (2016)
180. Duan, S., Ren, X., Zhang, X., Cheng, S., Hu, W.: Screen printing of flexible electronic devices. Prog. Chem. 30(4), 429-438 (2018)

181. Mohammed Ali, M., Maddipatla, D., Narakathu, B.B., Chlaihawi, A.A., Emamian, S., Janabi, F., Bazuin, B.J., Atashbar, M.Z.: Printed strain sensor based on silver nanowire/silver flake composite on flexible and stretchable TPU substrate. Sens. Actuators, A 274, 109-115 (2018)

182. Liang, J., Tong, K., Pei, Q.: A water-based silver-nanowire screen-print ink for the fabrication of stretchable conductors and wearable thin-film transistors. Adv. Mater. 28(28), 5986-5996 (2016)

183. Faddoul, R., Reverdy-Bruas, N., Blayo, A.: Formulation and screen printing of water based conductive flake silver pastes onto green ceramic tapes for electronic applications. Mater. Sci. Eng. B-Adv. 177(13), 1053-1066 (2012)

184. Xu, X., Liu, Z., He, P., Yang, J.: Screen printed silver nanowire and graphene oxide hybrid transparent electrodes for long-term electrocardiography monitoring. J. Phys. D. 52(45), 455401 (2019)

185. Finn, D.J., Lotya, M., Coleman, J.N.: Inkjet printing of silver nanowire networks. Acs Appl. Mater. Inter. 7(17), 9254-9261 (2015)

186. Choi, K., Yoo, J., Lee, C.K., Lee, S.: All-inkjet-printed, solidstate flexible supercapacitors on paper. Energ Environ Sci 9(9), 2812-2821 (2016)

187. Zhang, X., Jiang, X., Zhang, Z., Qin, H.: Fabrication of silver microstructures via electrohydrodynamic inkjet printing as customizable X-ray marker in bio-structure for biomedical diagnostic imaging. Int. J. Adv. Manuf. Tech. 114(1-2), 241-250 (2021)

188. Zhang, L.D.H.: Recent advances in probiotics encapsulation by electrospinning. ES Food Agrofor 2, 3-12 (2020)

189. Tsai, P.: Performance of Masks and Discussion of the Inactivation of SARS-CoV-2. Eng Sci 10, 1-7 (2020)

190. Elayappan, V., Murugadoss, V., Fei, Z., Dyson, P.J., Angaiah, S.: Influence of polypyrrole incorporated electrospun poly(vinylidene fluoride-co-hexafluoropropylene) nanofibrous composite membrane electrolyte on the photovoltaic performance of dye sensitized solar cell. Eng. Sci. 10, 78-84 (2020)

191. Yang, P., Zhao, H., Yang, Y., Zhao, P., Zhao, X., Yang, L.: Fabrication of $\mathrm{N}, \mathrm{P}$-codoped $\mathrm{Mo}_{2} \mathrm{C} /$ carbon nanofibers via electrospinning as electrocatalyst for hydrogen evolution reaction. ES Mater. Manuf. 7, 34-39 (2020)

192. Gao, C., Deng, W., Pan, F., Feng, X., Li, Y.: Superhydrophobic electrospun PVDF membranes with silanization and fluorosilanization co-functionalized CNTs for improved direct contact membrane distillation. Eng. Sci. 9, 35-43 (2020)

193. Angaiah, S., Murugadoss, V., Arunachalam, S., Panneerselvam, P., Krishnan, S.: Influence of various ionic liquids embedded electrospun polymer membrane electrolytes on the photovoltaic performance of DSSC. Eng. Sci. 4, 44-51 (2018)

194. Panneerselvam, P., Murugadoss, V., Elayappan, V., Lu, N., Guo, Z., Angaiah, S.: Influence of anti-reflecting nature of $\mathrm{MgF}_{2}$ embedded electrospun $\mathrm{TiO}_{2}$ nanofibers based photoanode to improve the photoconversion efficiency of DSSC. ES Energy Environ. 1, 99-105 (2018)

195. Han, G., Su, Y., Feng, Y., Lu, N.: Approaches for Increasing the beta;-phase concentration of electrospun polyvinylidene fluoride (PVDF) nanofibers. ES Mater. Manuf. 6, 75-80 (2019)

196. Gorgun, N., Ozer, C., Polat, K.: A new catalyst material from electrospun PVDF-HFP nanofibers by using magnetron-sputter coating for the treatment of dye-polluted waters. Adv. Compos. Hybrid Mater. 2(3), 423-430 (2019)

197. Panthi, G., Ranjit, R., Khadka, S., Gyawali, K.R., Kim, H., Park, M.: Characterization and antibacterial activity of rice grain-shaped $\mathrm{ZnS}$ nanoparticles immobilized inside the polymer 
electrospun nanofibers. Adv Compos Hybrid Mater 3(1), 8-15 (2020)

198. Xu, G., Chen, X., Zhu, Z., Wu, P., Wang, H., Chen, X., Gao, W., Liu, Z.: Pulse gas-assisted multi-needle electrospinning of nanofibers. Adv. Compos. Hybrid Mater. 3(1), 98-113 (2020)

199. Cheon, S., Kang, H., Kim, H., Son, Y., Lee, J.Y., Shin, H., Kim, S., Cho, J.H.: High-performance triboelectric nanogenerators based on electrospun polyvinylidene fluoride-silver nanowire composite nanofibers. Adv. Funct. Mater. 28(2), 1703778 (2018)

200. Song, J., Chen, M., Olesen, M.B., Wang, C., Havelund, R., Li, Q., Xie, E., Yang, R., Boggild, P., Wang, C., Besenbacher, F., Dong, M.: Direct electrospinning of Ag/polyvinylpyrrolidone nanocables. Nanoscale 3(12), 4966-4971 (2011)

201. Pan, C., Yang, T., Chen, Y., Su, C., Ju, S., Hung, K., Wu, I., Hsieh, C., Shen, S.: Fibers and conductive films using silver nanoparticles and nanowires by near-field electrospinning process. J Nanomater 2015, 1-5 (2015)

202. Xu, W., Xu, Q., Huang, Q., Tan, R., Shen, W., Song, W.: Fabrication of flexible transparent conductive films with silver nanowire by vacuum filtration and pet mold transfer. J. Mater. Sci. Technol. 32(2), 158-161 (2016)

203. Shen, L., Du, L., Tan, S., Zang, Z., Zhao, C., Mai, W.: Flexible electrochromic supercapacitor hybrid electrodes based on tungsten oxide films and silver nanowires. Chem. Commun. 52(37), 6296-6299 (2016)

204. Mushtaq, A., Cho, H., Ahmed, M.A., Rehman, M.S.U., Han, J.: A novel method for the fabrication of silver nanowires-based highly electro-conductive membrane with antifouling property for efficient microalgae harvesting. J. Membr. Sci. 590, 117258 (2019)

205. Ge, J., Yao, H., Wang, X., Ye, Y., Wang, J., Wu, Z., Liu, J., Fan, F., Gao, H., Zhang, C., Yu, S.: Stretchable conductors based on silver nanowires: improved performance through a binary network design. Angew Chem. Int. Edit. 52(6), 1654-1659 (2013)

206. Wu, C., Fang, L., Huang, X., Jiang, P.: Three-Dimensional Highly Conductive Graphene-Silver Nanowire Hybrid Foams for Flexible and Stretchable Conductors. Acs Appl Mater Inter 6(23), 21026-21034 (2014)
207. Xue, P., Liu, S., Shi, X., Sun, C., Lai, C., Zhou, Y., Sui, D., Chen, Y., Liang, J.: A Hierarchical Silver-Nanowire-Graphene Host Enabling Ultrahigh Rates and Superior Long-Term Cycling of Lithium-Metal Composite Anodes. Adv Mater 30(44), 1804165 (2018)

208. Wu, F., Li, Z., Ye, F., Zhao, X., Zhang, T., Yang, X.: Aligned silver nanowires as transparent conductive electrodes for flexible optoelectronic devices. J Mater Chem C 4(47), 11074-11080 (2016)

209. Shi, H., Hu, B., Yu, X., Zhao, R., Ren, X., Liu, S., Liu, J., Feng, M., Xu, A., Yu, S.: Ordering of disordered nanowires: spontaneous formation of highly aligned, ultralong ag nanowire films at oil-water-air interface. Adv. Funct. Mater. 20(6), 958-964 (2010)

210. Seo, Y., Kim, B.S., Ballance, W.C., Aw, N., Sutton, B., Kong, H.: Transparent and flexible electronics assembled with metallic nanowire-layered nondrying glycerogel. Acs Appl. Mater. Inter. 12(11), 13040-13050 (2020)

211. Klockner, W., Yadav, R.M., Yao, J., Lei, S., Aliyan, A., Wu, J., Marti, A.A., Vajtai, R., Ajayan, P.M., Denardin, J.C., Serafini, D., Melo, F., Singh, D.P.: Acetonitrile mediated facile synthesis and self-assembly of silver vanadate nanowires into 3D spongylike structure as a cathode material for lithium ion battery. J. Nanopart Res. 19(8), 288 (2017)

212. Small, W.R., Paunov, V.N.: Fabrication of electrically anisotropic agarose gels by dielectrophoretic assembly and encapsulation of silver nanowires. J. Mater. Chem. 18(18), 2082-2084 (2008)

213. Lim, C., Shin, Y., Jung, J., Kim, J.H., Lee, S., Kim, D.: Stretchable conductive nanocomposite based on alginate hydrogel and silver nanowires for wearable electronics. Appl Mater 7(3), 031502 (2019)

Publisher's Note Springer Nature remains neutral with regard to jurisdictional claims in published maps and institutional affiliations.

\title{
Authors and Affiliations
}

\author{
Lu Zhang ${ }^{1} \cdot$ Tingting Song ${ }^{1} \cdot$ Lianxu Shi $^{1} \cdot$ Nan Wen $\cdot$ Zijian Wu $^{2} \cdot$ Caiying Sun ${ }^{1} \cdot$ Dawei Jiang ${ }^{1} \cdot$ Zhanhu Guo $^{3}$ (D) \\ Lianxu Shi \\ 1xshi@nefu.edu.cn \\ $\triangle$ Caiying Sun \\ sundeyee@126.com \\ $\bowtie$ Zhanhu Guo \\ zguo10@utk.edu; nanomaterials2000@gmail.com \\ 2 Key Laboratory of Engineering Dielectrics and Its \\ Application, Ministry of Education, Harbin University \\ of Science and Technology, Harbin 150040, China \\ 3 Dept Chem Engn, Integrated Composites Lab ICL, \\ University of Tennessee System University of Tennessee \\ Knoxville Univ Tennessee, Knoxville, TN 37996, USA
}

1 College of Chemistry, Chemical Engineering and Resource Utilization, Northeast Forestry University, Harbin 150040, People's Republic of China 